\title{
Can you hear me? Impacts of underwater noise on communication space of adult, sub-adult and calf contact calls of endangered St. Lawrence belugas (Delphinapterus leucas)
}

\author{
Valeria Vergara, ${ }^{1}$ Jason Wood, ${ }^{2}$ Véronique Lesage, ${ }^{3}$ Audra Ames, ${ }^{4}$ Marie-Ana Mikus ${ }^{1}$ \& Robert Michaud ${ }^{5}$ \\ ${ }^{1}$ Marine Mammal Conservation Research Program, Ocean Wise Conservation Association, Vancouver, BC, Canada \\ ${ }^{2}$ SMRU Consulting, Vancouver, BC, Canada \\ ${ }^{3}$ Fisheries and Oceans Canada, Mont-Joli, QC, Canada \\ ${ }^{4}$ Fundación Oceanogràfic de la Comunitat Valenciana, Valencia, Spain \\ ${ }^{5}$ Group for Research and Education on Marine Mammals, Tadoussac, QC, Canada
}

\begin{abstract}
Noise and anthropogenic disturbances from vessel traffic are an important threat to the recovery of the endangered St. Lawrence Estuary (SLE) beluga population. The consequences of acoustic masking could be particularly adverse in the case of critical vocalizations that maintain contact between mothers and their dependent but mobile calves. This study models the communication range of adults, sub-adults and newborn beluga contact calls in the presence and absence of vessels in an important summering area for this population. Ambient noise measurements, a composite beluga audiogram and apparent source levels of adult/sub-adult and newborn calls, informed the model. Apparent source levels were estimated from received levels of contact calls produced by four individuals carrying digital acoustic tags in the SLE, Canada, and from received levels of calls recorded from two adults and a newborn calf at an aquarium, at known distances from a calibrated hydrophone. The median communication ranges were over 18 times larger for SLE adult and sub-adult calls than for newborn calls, with a 57 and $53 \%$ reduction in range in the presence of vessel noise, respectively. For newborn calls, this results in a median range of $170 \mathrm{~m}$ in vessel noise. These first estimates of the communication range of beluga vocalizations with a known function suggest that masking of the quiet calls of newborns by anthropogenic noise could impair mother-calf contact.
\end{abstract}

This article is part of the special cluster Beluga whales (Delphinapterus leucas): knowledge from the wild, human care and TEK, which has been funded by Mystic Aquarium, CAFF and the Norwegian Ministry of Climate and Environment.

\section{Correspondence}

Valeria Vergara, Marine Mammal Conservation Research Program, Ocean Wise Conservation Association, 845 Avison Way, Vancouver, BC V6G 3E2, Canada. E-mail:valeria.vergara@ocean.org

\section{Keywords}

Communication masking; communication range; active space; vessel traffic; noise pollution; anthropogenic noise
Abbreviations
AOA: angle of arrival
AOL: apparent output level
ASL: apparent source level
DFO: Fisheries and Oceans Canada
DTAG: digital acoustic recording tag
FFT: fast Fourier transform algorithm
IQ: interquartile
rms: root mean square
SD: standard deviation
SL: source level
SLE: St. Lawrence Estuary
SNR: signal-to-noise ratio
SPL: sound pressure level

\section{Introduction}

The harmful effects of anthropogenic noise on marine organisms as diverse as fish (Popper \& Hastings 2009), marine invertebrates (Nedelec et al. 2014) and marine mammals (Richardson et al. 1995; Southall et al. 2007) are a worldwide problem directly linked to the increasing industrialization of the oceans (Boyd et al. 2011). Belugas (Delphinapterus leucas) are one of the most acoustically active cetacean species, producing an extensive array of sounds for a variety of purposes, including maintaining contact and social communication, detecting prey and navigating (e.g., Sjare \& Smith 1986a, b; Vergara et al. 2010; Vergara \& Mikus 2019). Consequently, noise pollution from a number of sources (e.g., vessel traffic, seismic surveys, construction and dredging) represents a threat to belugas across much of their pan-Arctic range, given its potential for disrupting their behaviour or impairing their ability to communicate effectively.

The SLE beluga population is endemic to Canada and is reproductively and geographically isolated from other populations (Brown Gladden et al. 1999; Postma 2017). This population was legally listed as endangered under Canada's Species at Risk Act in 2016 because of its failure to recover from commercial and recreational hunting and recent decline (Mosnier et al. 2015), ongoing habitat degradation and projected increases in threats (COSEWIC 2014; Mosnier et al. 2015). In addition to a shortage of prey availability and high levels of contaminants, high noise levels and anthropogenic disturbance have been identified amongst the three main threats to the recovery of this endangered population (DFO 2017, 2020; Williams et al. 2017). 
In much of the Saguenay-St. Lawrence Seaway, belugas are exposed to noise from recreational and commercial vessel traffic (Simard et al. 2010; McQuinn et al. 2011 ; Gervaise et al. 2012; Lesage, McQuinn et al. 2014). Of the portion of the SLE beluga population exposed to commercial marine traffic (15-53\%), the vast majority $(72-81 \%)$ are females with calves or juveniles (Lesage, McQuinn et al. 2014). Elevated numbers of beluga newborn calves have been found dead in the SLE since 2008 (Lesage, Measures et al. 2014), accompanied by an increased mortality of adult females from peripartum complications (dystocia) since 2010 (Lair et al. 2016). There are concerns that noise and disturbance may be one of the factors implicated in these unusually high mortalities (DFO 2014). The increased calf mortalities reported in 2010 and 2012 coincided with good weather conditions (favourable for boating) and peaks in recreational boating activity, with higher than usual co-occurrences between belugas and boats in the critical habitat of belugas during summer months (Ménard et al. 2014).

One of the potentially adverse effects of increases in anthropogenic noise levels is acoustic masking, the reduction of the effective range over which a communication signal can be detected and decoded by conspecifics (e.g., Clark et al. 2009). This effective range is also known as the communication space of a signal, the area or volume around the vocalizing individual within which effective communication with conspecifics can be expected to occur (Marten \& Marler 1977; Clark et al. 2009). It is largely a function of a signal's SL (the sound level at $1 \mathrm{~m}$ from the vocalizing animal on the acoustic axis [Au 1993]), the levels of background noise, the transmission loss of the signal between the signaler and the receiver, the critical frequency bandwidth of the animal's auditory filter (Reichmuth 2012; Erbe et al. 2016) and the hearing capabilities of the listener (Brenowitz 1982; Miller 2006; Tervo et al. 2012).

The effects of noise on communication space have been documented for a few high-frequency odontocete species (a functional hearing group [see Southall et al. 2019]), including short-finned pilot whales (Globicephala macrorhynchus; Jensen, Bejder, Wahlberg, Aguilar de Soto et al. 2009), bottlenose dolphins (Tursiops truncatus; Jensen, Bejder, Wahlberg, Aguilar de Soto et al. 2009; Jensen et al. 2012), killer whales (Orcinus orca; Bain $\&$ Dahlheim 1994; Au et al. 2004; Miller 2006) and belugas (Gervaise et al. 2012). The single beluga study that estimated the maximum communication range of a beluga signal in natural and variable ambient noise conditions used a hypothetical vocalization with an assumed central frequency of $2.5 \mathrm{kHz}$ (Gervaise et al. 2012). Although theoretical exercises with hypothetical signals are useful, evaluating the effects of noise on a commonly used signal of known acoustic characteristics and function would provide greater insight into beluga communication behaviour and the consequences of noise masking.

Despite many descriptions of the beluga whale's extensive vocal repertoire (Fish \& Mowbray 1962; Sjare \& Smith 1986a; Faucher 1988; Angiel 1997; Karlsen et al. 2002; Belikov \& Bel'kovich 2006, 2008; Panova et al. 2012), and some progress correlating call rates and broad call classes with general behavioural states (e.g., Sjare $\delta$ Smith 1986b; Belikov \& Bel'kovich 2003), little is known about the particular function of most beluga communication signals. Those that function to establish or maintain contact between individuals are a notable exception, as much is currently known about these signals. A mounting body of work has established that belugas use broadband (200 Hz-144 kHz), long-duration (typically > 1s) pulsed contact calls for group cohesion during isolation (Vergara et al. 2010; Morisaka et al. 2013; Mishima et al. 2015; Panova et al. 2017; Vergara \& Mikus 2019) and for mother-calf contact (Vergara \& Barrett-Lennard 2008; Vergara et al. 2010; Ames \& Vergara 2020). The broadband acoustic structure typical of beluga contact calls is shared with narwhals (Monodon monoceros), a closely related species (Shapiro 2006), and may have evolved to minimize masking by ambient noise in the Arctic (Vergara et al. 2010). This broadband structure differs markedly from the narrowband contact signals produced by delphinids, such as bottlenose dolphins (Caldwell \& Caldwell 1965; review in Janik \& Sayigh 2013), Indo-Pacific humpback dolphins (Sousa chinensis; Van Parijs \& Corkeron 2001) and Guiana dolphins (Sotalia guianensis; Duarte de Figueiredo \& Simão 2009; Lima \& Le Pendu 2014).

Beluga contact calls can be complex-with a stereotyped component (often tonal or pulsed-tonal) in the lower frequencies (below $20 \mathrm{kHz}$ ) overlapping the broadband pulse train-or simple, with only the pulse train but no overlapping component (Vergara \& Mikus 2019). There is preliminary evidence that the stereotyped component of complex contact calls may function as a vocal signature, encoding identity at the individual or familial level (Panova et al. 2017; Vergara \& Mikus 2019). However, newborn beluga calves only produce simple pulse trains, developing their complex contact call as they age (Vergara \& Barrett-Lennard 2008). Their initial pulse trains, the only call type that newborn belugas produce, are as broadband as the adult contact calls, but with less acoustic energy at high frequencies and lower pulse repetition rates compared to adult contact calls (Vergara \& Barrett-Lennard 2008; Ames \& Vergara 2020).

Given that acoustic contact is critical in visually limited aquatic environments, the consequences of acoustic masking could be particularly adverse in the case of vocalizations that function to maintain contact between 
mothers and their dependent but precocious calves (Kasuya 1995). Yet, the specific impacts of noise on mother-calf contact signals have never been studied in belugas and have been studied in only a few other cetaceans, for example, North Atlantic right whales (Eubalaena glacialis; Tennessen \& Parks 2016). Here, we model the communication space of both adults/sub-adults and newborn beluga contact calls in the acoustic environment of Baie Sainte-Marguerite, an area of high residency (Lefebvre et al. 2012) for females and calves in the Saguenay-St. Lawrence Marine Park, where vessel traffic can be high at times during summer. We estimated the detection range of adult and calf contact calls under natural background noise conditions and modelled how this range changed in the presence of vessel noise. Our findings shed light on the extent to which masking can compromise the mother-calf bond, which can inform species management plans both in the SLE and throughout the beluga's pan-Arctic range.

\section{Methods}

\section{ASLs of beluga contact calls}

To evaluate the communication space of a signal, one would ideally need to know the SL of that signal, defined as its SPL at a nominal distance of $1 \mathrm{~m}$ from the source, expressed in $\mathrm{dB}$ re $1 \mu \mathrm{Pa}$ at $1 \mathrm{~m}$. When recordings at $1 \mathrm{~m}$ from the animal cannot be obtained, received SPLs are used to calculate the ASLs, defined as the back-calculated SPLs at $1 \mathrm{~m}$ distance from the sound source at an unknown angle from the acoustic axis (Mohl et al. 2000; Jensen, Bejder, Wahlberg \& Madsen 2009; Wang et al. 2016).
Here, we used received levels of contact calls recorded from adult and sub-adult SLE belugas carrying DTAGs (Johnson \& Tyack 2003) to estimate ASLs (details below). In addition, to have a more complete understanding of the distribution of ASLs used by adult and newborn belugas when they emit contact calls, we estimated contact call ASLs from recordings made at an aquarium (Oceanogràfic, Valencia, Spain) at known distances from a calibrated hydrophone (specifications provided in the following sections). In all cases, the broadband ASL estimates integrated calls from $500 \mathrm{~Hz}$ to $100 \mathrm{kHz}$, to cover the majority of energy contained in beluga broadband contact calls while also matching the frequency response and sampling rates of the acoustic recorders used in this study. The ASL estimates were calculated both in broadband (from $500 \mathrm{~Hz}$ to $100 \mathrm{kHz}$ ) for comparison with other studies as well as in 1/12 octave bands for our communication range estimates (see sections below on rationale for 1/12 octaves and methods for communication range estimates). The contact call data sets and ASL estimation are described below, and representative spectrograms are provided in Fig. 1.

SLE adult and sub-adult contact calls. ASLs were estimated from 53 contact calls identified in recordings from two adults (20 and 13 calls) and two sub-adults ( $\geq$ four years old; 14 and six calls) carrying DTAGs. The sex of the animals was unknown, although the two adults were likely males, as inferred from the composition of their groups (predominantly large adults, no calves). The DTAGs were deployed during the summers of 2018 and 2019, from an $8 \mathrm{~m}$ research vessel, using a handheld carbon fibre pole to attach the tag to a whale via suction cups (Fig. 2). The DTAGs record sounds continuously
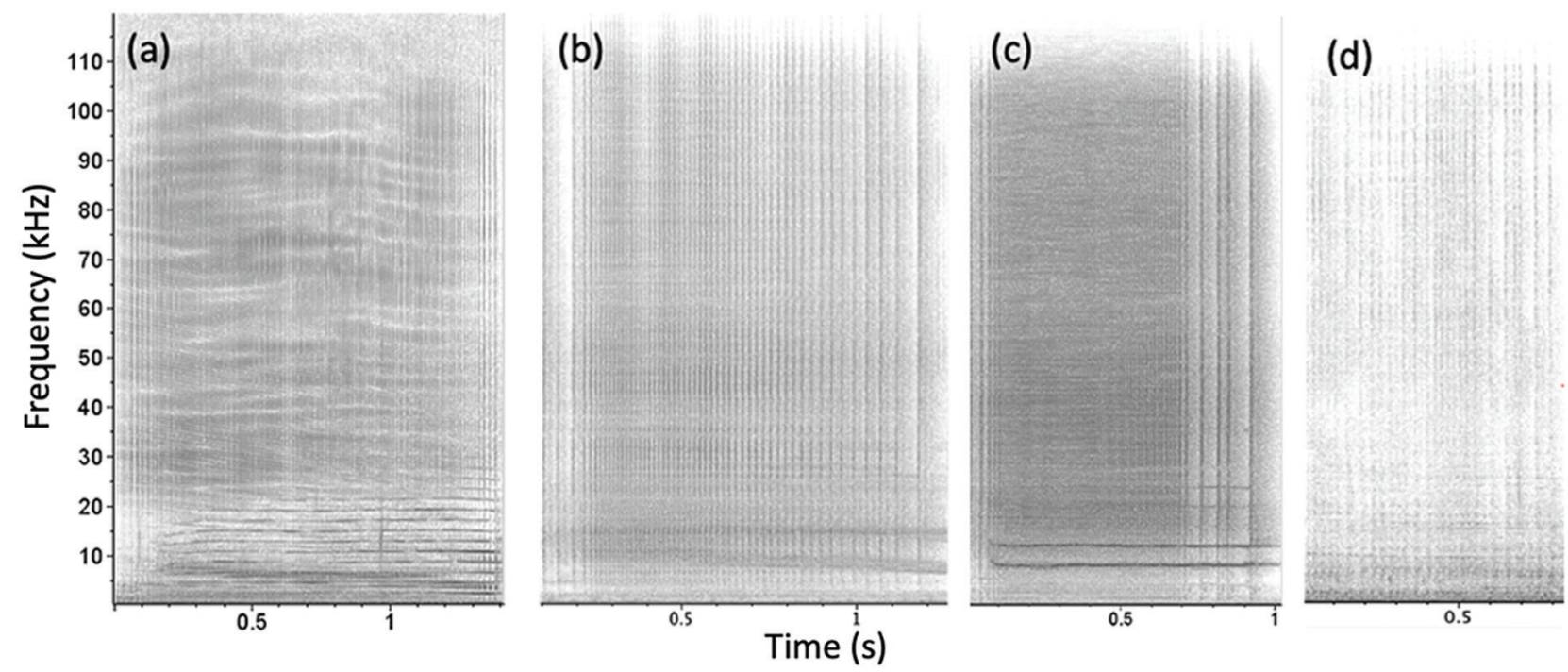

Fig.1 Representative spectrograms of the contact call data sets used for our ASL estimates (FFT at 2048 points with a 50\% overlap, Hann window): (a) SLE (DLT18003), (b) Oceanogràfic aquarium female, (c) Oceanogràfic aquarium male, (d) Oceanogràfic aquarium three-day-old calf. 
through two hydrophones positioned $43 \mathrm{~mm}$ apart, at a sampling rate of $240 \mathrm{kHz}$ per channel. Only one individual was tagged at a time. The DTAGS were equipped with a VHF beacon that facilitated following the tagged whale and tracking and recovering the device when it released. The recording period lasted 4-13.5 hours (until the tag released), and focal follows of the tagged individuals were performed when possible. Each time the tagged whale was spotted during a surfacing sequence, the observer noted whether the animal was alone or in association with others.

To identify contact calls in recordings of tagged whales, we analysed a total of 93 hours and 22 minutes of acoustic data from 22 tagging events. Contact calls were identified visually (following Vergara \& Mikus 2019) using Raven Pro 1.5 software (Cornell Lab of Ornithology) and adhered to the following criteria: (a) produced in series (i.e., two or more of the same calls within 10 seconds), with a series appearing more than once in the recording; (b) stereotyped (i.e., signals in a repertoire that have little variability in acoustic parameters between utterances); (c) little fluctuation in amplitude within a series (as large fluctuations could indicate another animal swimming at various distances and orientations from the tagged whales); (d) predominant contact call type if more than one type was identified in the recording and (e) SNRs of more than 10 $\mathrm{dB}$, to exclude faint contact calls from distant animals (see Saddler et al. 2017). The SNR was calculated as the difference between the rms 'inband power' of the signal in the frequency band $500 \mathrm{~Hz}$ to $100 \mathrm{kHz}$, which contains most of the sound of interest for the broadband contact calls, and the inband power of the ambient noise period immediately preceding or following the signal (in the same frequency range and for a duration as close as possible to the signal).

Once contact call series were identified in DTAGs, those produced by the tagged beluga were further distinguished from those of nearby whales based on the AOA

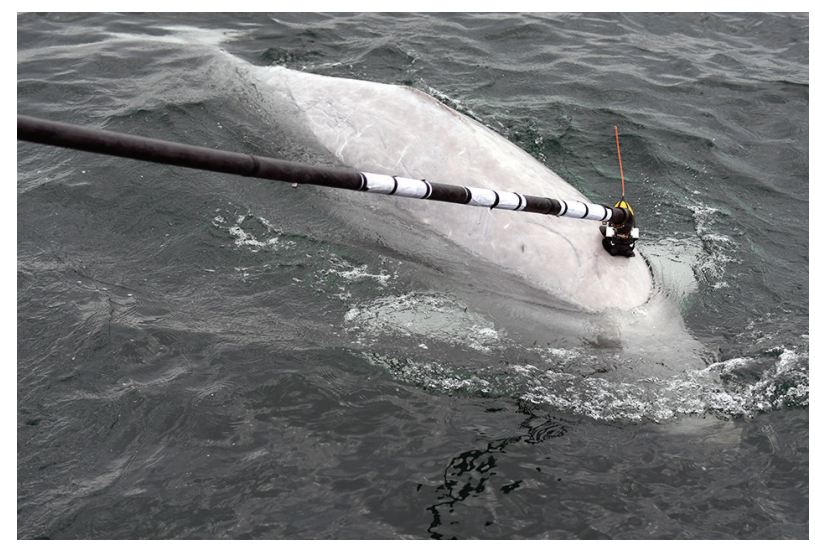

Fig. 2 DTAG deployment on a sub-adult beluga, using a handheld carbon fibre pole, within $1 \mathrm{~m}$ of the blowhole.
(Johnson et al. 2006). This was calculated with the following formula from Johnson et al. (2006): $\mathrm{AOA}=$ $\sin ^{-1}(\tau \mathrm{c} / \mathrm{d})$, where $\mathrm{c}$ is the speed of sound in seawater, $\mathrm{d}$ is the hydrophone separation $(43 \mathrm{~mm})$ and $\tau$ is the time delay between the two hydrophone signals, measured by cross-correlation. Only contact calls with consistent AOAs that were \pm 10 degrees from the mean AOA were considered as being produced by the tagged beluga (Jensen et al. 2011 ; Perez et al. 2017). This condition was met by contact call series in four of the DTAGs $(n=53$ contact calls, mean SNR $24 \pm 7 \mathrm{~dB}$ ). For three of the four DTAG carriers for which identified contact calls met the AOA condition, visual observations and the scarcity of other calls in the recordings indicated a lack of association with other individuals at the time of contact call production.

We calculated the AOLs of the identified contact calls, defined as the received levels on the DTAG in a fixed but off-axis position on the body of the whale (Madsen et al. 2005; Jensen 2020). Odontocetes generate sound below the blowhole, when air passes through two structural complexes formed by a fatty bursa embedded in a pair of phonic lips, causing them to open and slap together, creating vibrations (Cranford et al. 1996). Given that the DTAGs were placed each time within $1 \mathrm{~m}$ of the blowhole but not exactly at $1 \mathrm{~m}$ (Fig. 2), and always behind rather than in front of the sound generating structure and thus not in the path of the forward-directed sound beam (Madsen et al. 2005), we considered the AOLs as simple approximations of the ASLs for our model. The DTAG hydrophone channel with the higher amplitude was used for measurements of AOLs.

Oceanogràfic adult contact calls. We calculated ASLS for 16 contact calls from an adult female, Yulka $(n=10)$, and an adult male, Kairo $(n=6)$, recorded in isolation at Oceanogràfic, an aquarium in Valencia (Spain), at known distances from the hydrophone (ranging 12-15 $\mathrm{m})$, with the animals facing the hydrophone or at a slight angle to it. We used a calibrated icListen Ocean Sonics digital hydrophone sampling at a rate of $256 \mathrm{kHz}$ (24bit resolution). The hydrophone was in a permanent position in the pool, at a depth of $1 \mathrm{~m}$. We used cylindrical spreading to approximate transmission loss, as follows: RL $+10 *$ LOG $10(\mathrm{D})$, whereby RL is the received level and $\mathrm{D}$ is the distance from the hydrophone.

Oceanogràfic newborn contact calls. We used Ames \& Vergara's (2020) ASLs from 65 broadband pulse trains produced by a male beluga calf, Kylu (born at Oceanogràfic on 15 November 2016), during his first month of life (days 2-28). The same digital sampling set-up as that described for the Oceanogràfic adult calls was used. The vocalizations were assigned to the calf when he was isolated in one of the pools or if they coincided with the emission of bubble streams, 
a methodology commonly used in vocal development studies of odontocetes (McCowann \& Reiss 1995; Bojanowski et al. 2000; Killebrew et al. 2001; Mello $\delta$ Amundin 2005; Morisaka, Shinohara \& Taki 2005; Fripp \& Tyack 2008; Vergara \& Barrett-Lennard 2008; Bowles et al. 2015). The calf produced broadband pulse trains almost exclusively during his first month, presumably rudimentary contact calls (Ames \& Vergara 2020). Ames $\delta$ Vergara subsampled those pulse trains for which the distance of the calf to the hydrophone during sound production was known (distances ranged 1.5-17 m), and during which the calf was either facing the hydrophone or at a slight angle to it, but not facing completely away from the hydrophone (all $180^{\circ}$ angle orientations were discarded). Cylindrical spreading was used to approximate transmission loss, in the same way as for the aquarium adults, described above.

Critical bandwidth and audiogram of receiver. We used the beluga audiogram from Erbe et al. (2016) based on measured hearing thresholds pooled from all individuals tested for both AEP and behavioural methods (White et al. 1978; Awbrey et al. 1988; Johnson et al. 1989; Popov \& Supin 1990; Erbe \& Farmer 1998; Klishin et al. 2000; Ridgway et al. 2001; Finneran et al. 2002; Finneran et al. 2005; Mooney et al. 2008; Castellote et al. 2014). The critical bandwidth measures the width of the auditory filter within which masking can occur. Noise effectively masks a signal when it is within a critical bandwidth of frequency around the desired signal. For belugas, 1/12 of an octave is likely the best current estimate of the noise-masking potential (Erbe 2000).

\section{Ambient noise recordings}

Ambient noise recordings took place at Baie SainteMarguerite, a small delta at the confluence of the Saguenay and Sainte-Marguerite Rivers, 12 nautical miles upstream from the mouth of the Saguenay Fjord, in the SLE, Canada (Fig. 3). This bay is an area of high residency for female belugas and their calves, used for socialization and resting and where females care for their young (Lefebvre et al. 2012; DFO 2018). The depth is $118 \mathrm{~m}$ in the centre of the Saguenay at its deepest channel, decreasing to $10 \mathrm{~m}$ closer to the head of the Sainte Marguerite River. Only 1.5 km separate the bay's intertidal zone from the opposite shore of the Saguenay River, and this, in addition to the steep bathymetry of the area, means that any vessel entering the bay or transiting the river, ensonifies the whole area from shore to shore.

We used two factory-calibrated passive acoustic monitoring devices. A SoundTrap HF300 (Ocean Instruments,

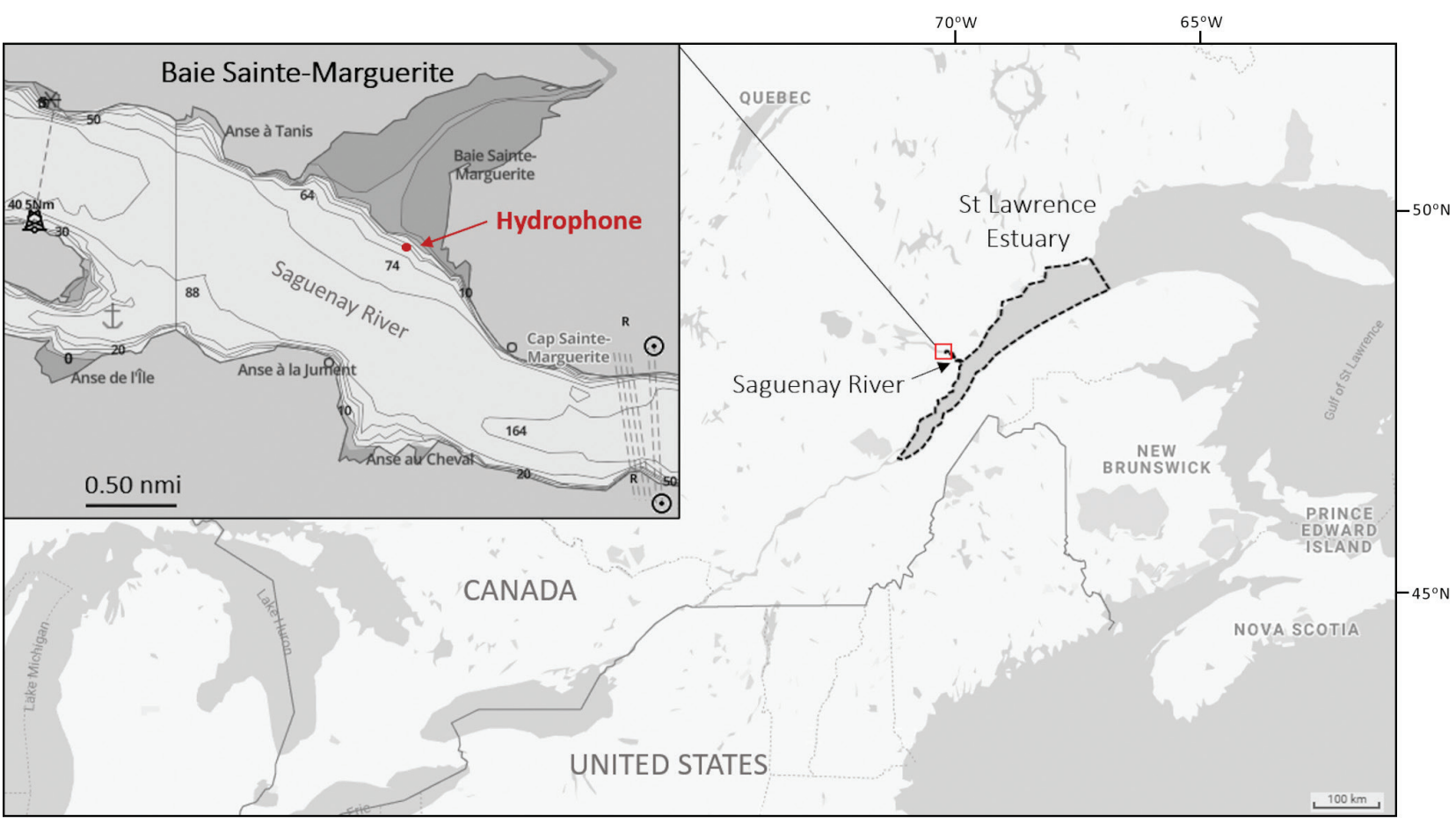

Fig. 3 The SLE study area, Canada, indicating the location of the hydrophone in Baie Sainte-Marguerite, an area of high residency for SLE beluga females and calves, where ambient noise was recorded in this study (numbers indicate depth in metres). 
New Zealand) with a flat frequency response from $20 \mathrm{~Hz}$ to $150 \mathrm{kHz}( \pm 3 \mathrm{~dB}),-172.7 \mathrm{~dB}$ re $1 \mathrm{~V} / \mu \mathrm{Pa}$ sensitivity, 16-bit resolution and a sampling rate of $288 \mathrm{kHz}$ was deployed at a depth of 15-20 m. The device recorded continuously during the three following periods in the summer of 2017: 24 July to 29 July, 31 July to 8 August and 9 August to 18 August, for a total of 23 days of recordings. The SoundTrap was tethered to our observation platform (described below) with a sink line, moored to an anchor and attached to a buoy to keep it suspended just above the riverbed. In addition, on days when we accessed the observation tower, we deployed a calibrated icListen HF hydrophone (Ocean Sonics), with a frequency response of $10-200 \mathrm{kHz}, 24$-bit resolution and a sampling rate of $256 \mathrm{kHz}$. This device also streamed sound in real time through a speaker so that we could listen to the belugas while conducting visual observations.

\section{Visual observations}

We conducted visual observations from a 6-m high observation tower, with a $1.5 \times 3 \mathrm{~m}$ platform, erected during the spring tide window at the mouth of the SainteMarguerite River, at $48^{\circ} 15^{\prime} 2.83^{\prime \prime} \mathrm{N} 69^{\circ} 58^{\prime} 0.83^{\prime \prime} \mathrm{W}$. Except for the periods coinciding with very low tides, the tower was surrounded by water and the whales often swam near it, undisturbed by our presence.

We used a fixed two-minute interval scan sampling technique (Martin \& Bateson 2007) to document vessel data (number and type of boats running during the two-minute interval, and distance category from the hydrophone). Every 30 minutes, we also documented the presence or absence of belugas in the bay, number of animals in the herd and herd composition.

\section{Herd composition and contact call usage}

In order to examine the extent of contact call usage in the repertoire of SLE belugas and evaluate whether this call type is favoured in herds of females and calves, we paired data on contact call production and herd composition. We analysed 24.5 hours of recordings obtained on 22 different days of visual observations of beluga herds in Baie Sainte-Marguerite in 2017 and 2018. Herd composition was noted for all herd encounters and divided into the following two general categories: (a) all adults and subadults, (b) adults, sub-adults and calves and/or yearlings. Contact calls were identified in spectrograms using Raven Pro 1.5 (Cornell Lab of Ornithology), following Vergara \& Mikus (2019). A chi-square test of homogeneity was conducted to test the difference in the proportion of contact call usage in the two types of herd using SPSS statistics software (Laerd Statistics 2016).

\section{Noise profile analysis}

We used MATLAB R2017b and scripts modified from Merchant et al. (2015) to analyse 23 days of SoundTrap data from the three contiguous deployments, splitting the wav files into one-minute duration files and measuring power spectral density levels for each one-minute file with an FFT window size that matched the sampling rate (288 000 samples), a 50\% overlap and Welch's averaging (Merchant et al. 2015). This is the first step required to model the communication range of adult and calf contact calls under various noise level conditions in Baie Sainte-Marguerite.

We manually reviewed 241 hours and 20 minutes of SoundTrap recordings while visualizing them on spectrograms. This amounts to about 10 of the 23 days of deployment, including 12.3 daytime periods (05:30 to 20:00) and 6.6 nighttime periods (20:00 to 05:30). We crosschecked the recordings with our visual notes (for the daytime periods) and verified potential vessel and/or beluga presence in the bay by visual and aural inspection of the audio recordings, in order to have a sample of time periods with (1) natural ambient noise (neither boat noise nor whale sounds), (2) boats (but no whales), (3) whales (but no boats) and (4) both boats and whale sounds. For this paper, we considered one or more boats running up or down the river within $2 \mathrm{~km}$ of the hydrophone as 'boats present.' Familiarizing ourselves with boat noise confirmed by visuals to be within $2 \mathrm{~km}$ of the hydrophone during daytime periods enabled us to approximate the same distance when relying exclusively on spectrograms for nighttime periods (note that vessel noise was very infrequent at night; see results).

\section{Communication range estimates}

The communication range of each contact call was estimated as the maximum range at which the signal is still audible ( $\mathrm{SNR}>0 \mathrm{~dB}$ ) by a conspecific in at least one of the 1/12 octave bands analysed, after accounting for transmission loss (adapted from Miller 2006 and Wang et al. 2016). For comparison, we also estimated the detection range within which all 1/12 octave bands in the broadband calls (integrated from $500 \mathrm{~Hz}$ to $100 \mathrm{kHz}$ ), and half of the 1/12 octave bands, would still be audible.

To obtain estimates of the communication space of beluga contact calls, we used ALS estimations of the contact calls, transmission loss, our measurements of ambient noise under no-boat conditions and when boats were present in Baie Sainte Marguerite, and the beluga audiogram from Erbe et al. (2016). For the propagation of the beluga contact calls, we used the approximate spreading loss coefficient for the Saguenay River reported in Fig. 8 
of McQuinn et al. (2011), ca. 18 dB. Frequency dependent absorption was also included in our calculations. In each 1/12 octave band and at each distance, either the beluga hearing curve or the noise level, whichever was greater, was subtracted from the estimated beluga contact call received level in that $1 / 12$ octave band. This resulted in a signal excess, or the number of $\mathrm{dB}$ that the contact call would be above the noise level or hearing curve at that distance for that 1/12 octave band. The model considered the distance at which the signal excess reached zero in all 1/12 octave bands analysed (see Erbe [2000] for measurements of beluga hearing thresholds in noise that corroborate Fletcher's equal power assumption of $\mathrm{SNR}=0 \mathrm{~dB})$. For each contact call, a MATLAB code calculated signal excess for each one-minute noise file for both 'no boat' and 'boat' conditions (when no belugas were present, to avoid conspecific masking as a confounding factor), to generate distribution curves of all possible communication ranges in all noise scenarios in Baie Sainte-Marguerite. In permutating every contact call and every one-minute noise file, the model took into account all of the variability in our data. For example, to estimate communication ranges for the DTAG calls $(n=$ 53 ) in the presence of boat noise (2220 minutes with boats and no whales), the model ran 117660 permutations $\left(2220^{* 53}\right)$, and to estimate range in quieter conditions (9978 minutes with no boats and no whales), the model ran 528834 permutations $(9978 * 53)$.

\section{Results}

\section{Herd composition and contact call usage}

Of the 22 different herd encounters in Baie SainteMarguerite (on 22 different days), 12 consisted of adults, sub-adults and newborn calves (mean herd size $39 \pm 17$ ), one consisted of adults, sub-adults and yearlings (herd size 30) and nine had only large adults (often males) and sub-adults, with neither newborns nor yearlings (mean herd size $18 \pm 10$ individuals). A total of 26753 calls emitted during these 22 herd encounters were categorized into 'contact call' or 'other type' for herds with versus without newborns/yearlings. There was a statistically significant difference between the proportion of contact calls produced by herds with calves or yearlings compared to herds comprised of older individuals $\left(\chi^{2}(1)=\right.$ 97.53, $p<0.001$ ), with contact calls being used significantly more often in herds with newborns and/or yearlings $(11.8 \%)$ than in adult/sub-adult herds $(6 \%)$.

\section{Characteristics of the Baie Sainte-Marguerite soundscape}

The Leq (equivalent rms sound level) showed some short duration but high-amplitude events when integrated across the 23 days of data (Fig. 4). The bimodal distribution between $100 \mathrm{~Hz}$ and $10 \mathrm{kHz}$ may be driven by beluga calls

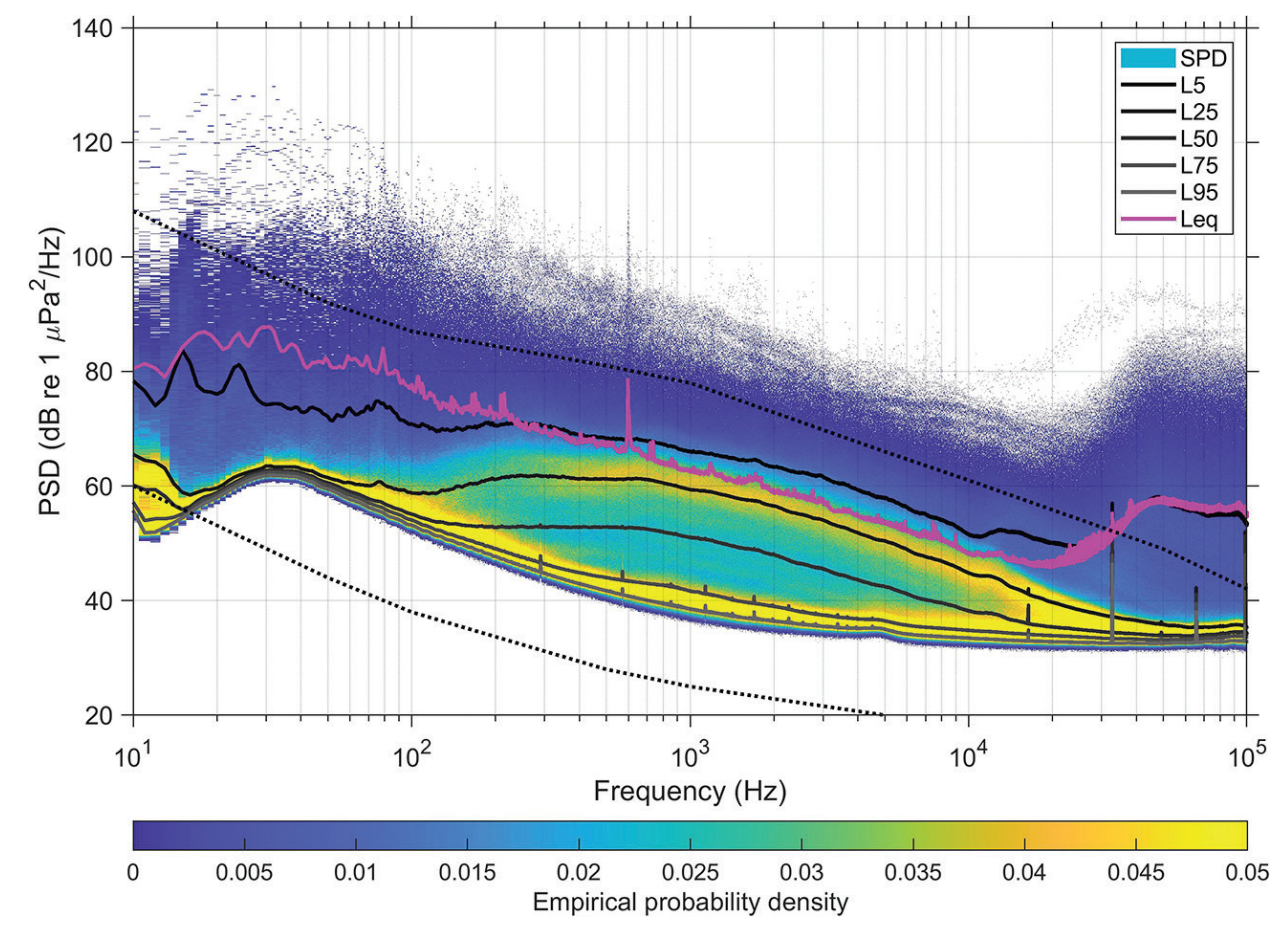

Fig. 4 Power spectral density levels over the 23-day recording period at Baie Sainte-Marguerite. SPD is the spectral probability density. L5, L25, etc. are exceedance levels (i.e., L5 means sound levels exceed this 5\% of the time). Leq is the rms level. Wenz lines are the limits of prevailing noise (Wenz 1962). 
or boat noise. Figure 5 provides the broadband noise cumulative probability plots for 241 hours of recordings that were manually verified and split (minute by minute) into the four pre-defined categories. When belugas were present in the bay, vessel noise emanating from one or more vessels was confirmed $23 \%$ of the time $(520 / 2271$ minutes $)$. In total, vessel noise was confirmed $19 \%$ of the time (2744/14 479 minutes). Splitting the manually verified recordings into daytime and nighttime hours (sunrise 05:30 to sunset 20:00), vessel noise occurred during $24 \%$ of the daytime recordings (2540/10 729 minutes) and 5\% of the nighttime recordings (204/3751 minutes).

\section{Broadband ASLs of beluga contact calls}

Adult and sub-adult contact calls. The sample of 53 complex contact calls recorded from temporarily tagged

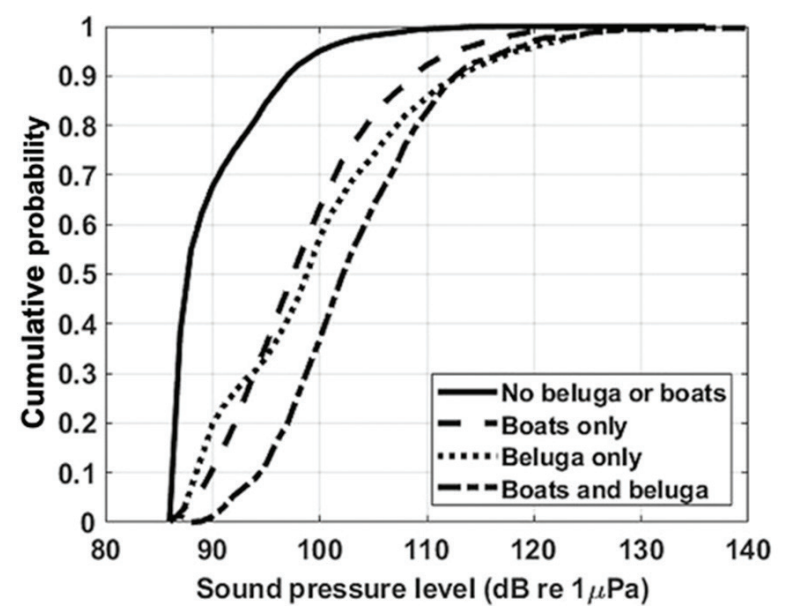

Fig. 5 Broadband sound pressure level cumulative probability plots for the four manually verified periods for 241.33 hours of recordings. adult and sub-adult belugas in the SLE had a mean ASL of $150.1 \pm 7.5 \mathrm{~dB}$ re $1 \mu \mathrm{Pa}$ at $1 \mathrm{~m}$ and a median of $150.3 \mathrm{~dB}$ re $1 \mu \mathrm{Pa}$ at $1 \mathrm{~m}$, slightly louder than the ASLs for the sample of 16 complex contact calls produced by the two adult belugas housed at Oceanogràfic, with a mean of $146.8 \pm 5.8 \mathrm{~dB}$ re 1 $\mu \mathrm{Pa}$ at $1 \mathrm{~m}$ and a median of $147.9 \mathrm{~dB}$ re $1 \mu \mathrm{Pa}$ at $1 \mathrm{~m}$. Table 1 lists the ASLs of calls produced by each individual, in addition to the peak frequencies and duration of the calls.

Newborn calls. The pulse trains emitted by the newborn beluga calf during its first month of life had a mean ASL of $126.7 \pm 8.4 \mathrm{~dB}$ re $1 \mu \mathrm{Pa}$ at $1 \mathrm{~m}$ and a median of $127 \mathrm{~dB}$ re 1 $\mu \mathrm{Pa}$ at $1 \mathrm{~m}$, about $20 \mathrm{~dB}$ quieter than the ASLs from adult contact calls in the same aquarium (Table 1). A detailed study of this calf's vocal development showed a significant increase of ASLs with age (Ames \& Vergara 2020), with a $12 \mathrm{~dB}$ increase in mean ASL after the first week of life: ASL increased from an average of $120 \pm 5.8 \mathrm{~dB}$ re $1 \mu \mathrm{Pa}$ at $1 \mathrm{~m}$ and a median of $121.1 \mathrm{~dB}$ re $1 \mu \mathrm{Pa}$ at $1 \mathrm{~m}$ from days 2 to 7 to an average ASL of $132.7 \pm 5.1 \mathrm{~dB}$ re $1 \mu \mathrm{Pa}$ at $1 \mathrm{~m}$ and a median of $132.8 \mathrm{~dB}$ re $1 \mu \mathrm{Pa}$ at $1 \mathrm{~m}$ from days 14 to 28 .

\section{Communication range}

Adult and sub-adult contact calls. The estimated communication range of SLE adult/sub-adult beluga broadband contact calls in the absence of boat noise had a median of $6.7 \mathrm{~km}$, based on the $1 / 12$ th octave band audible to the greatest distance (IQ range 3.4-20.9 km, Fig. 6, Table 2). In a noisy environment, with levels like those recorded in Baie Sainte-Marguerite during summer, the estimated communication distance for adult and sub-adult contact calls could be reduced by $57 \%$, to a median range of $2.9 \mathrm{~km}$, although this distance could be as short as $1.2 \mathrm{~km}$ (Table 2). These ranges were larger than the modelled communication ranges for the

Table 1 Beluga contact call data sets, peak frequency, duration (delta time) and ASLs. All calls were broadband and had a maximum frequency equal to the Nyquist frequency $(120-128 \mathrm{kHz})$.

\begin{tabular}{|c|c|c|c|c|c|c|c|c|c|}
\hline \multirow{2}{*}{ Data set } & & \multirow{2}{*}{$n$} & \multirow{2}{*}{$\begin{array}{c}\text { Contact call } \\
\text { type }\end{array}$} & \multicolumn{2}{|c|}{ Peak frequency $(\mathrm{kHz})$} & \multicolumn{2}{|c|}{ Delta time (s) } & \multicolumn{2}{|c|}{$\mathrm{ASL}$ (dB re $1 \mu \mathrm{Pa}$ at $1 \mathrm{~m}$ ) } \\
\hline & & & & Mean \pm SD & Median & Mean \pm SD & Median & Mean \pm SD & Median \\
\hline \multirow[t]{4}{*}{ SLE (DTAGS) } & $\begin{array}{l}\text { DLT18002 } \\
\text { (sub-adult) }\end{array}$ & 6 & Complex & $2.1 \pm 1.5$ & 2.1 & $0.9 \pm 0.2$ & 0.9 & $151.4 \pm 1.3$ & 150.8 \\
\hline & $\begin{array}{l}\text { DLT18003 } \\
\text { (sub-adult) }\end{array}$ & 14 & Complex & $7.4 \pm 4.2$ & 8.4 & $1.2 \pm 0.5$ & 1.4 & $140.2 \pm 1.1$ & 140.1 \\
\hline & $\begin{array}{l}\text { DLT18011 } \\
\text { (adult) }\end{array}$ & 13 & Complex & $5.3 \pm 2.3$ & 4.1 & $0.7 \pm 0.04$ & 0.7 & $150.2 \pm 2.4$ & 150.2 \\
\hline & $\begin{array}{l}\text { DLT19008 } \\
\text { (adult) }\end{array}$ & 20 & Complex & $5.1 \pm 0.7$ & 4.8 & $1.0 \pm 0.3$ & 1.0 & $156.6 \pm 5.6$ & 157.7 \\
\hline \multirow[t]{3}{*}{ Aquarium } & Adult female & 13 & Complex & $12.2 \pm 1.1$ & 12.2 & $1.1 \pm 0.1$ & 1.2 & $144.0 \pm 4.6$ & 144.6 \\
\hline & Adult male & 6 & Complex & $11.3 \pm 1.6$ & 12.0 & $1.4 \pm 0.2$ & 1.4 & $151.6 \pm 4.2$ & 150.6 \\
\hline & Newborn calf & 65 & Simple & $5.6 \pm 8.6$ & 3.9 & $0.7 \pm 0.4$ & 0.7 & $126 \pm 8.4^{a}$ & $127.0^{a}$ \\
\hline
\end{tabular}

aMean and median ASL for the newborn calf from Ames \& Vergara (2020). 

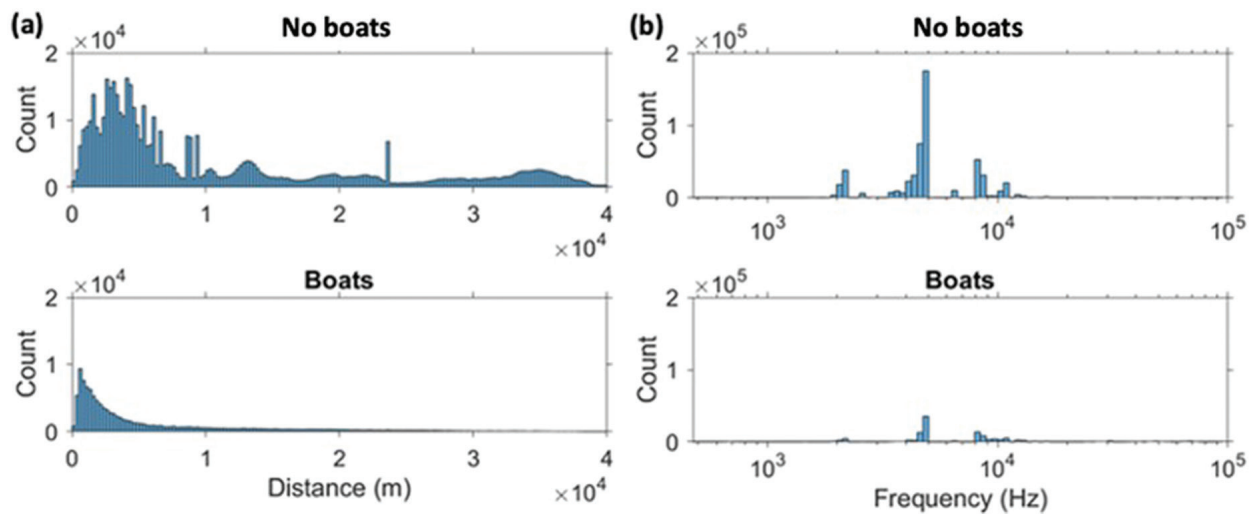

Fig. 6 Histograms showing distribution curves of modelled communication range of adult/sub-adult beluga contact calls produced by belugas carrying DTAGs (SLE). (a) Maximum communication distances under 'no boats' (top) and 'boats' (bottom) scenarios. (b) 1/12 octave centre frequencies of maximum communication distances under 'no boats' (top) and 'boats' (bottom) scenarios. The count on the $y$ axis is the number of model iterations for each combination of one call and one-minute noise file that falls in a specific distance or frequency bin.

Table 2 Median and interquartile ranges for estimates of communication range of beluga contact calls under 'no boats' and 'boats' noise conditions, indicating percentage reduction in range under noise levels like those recorded when boats were present in Baie Sainte Marguerite. Median and interquartile ranges for the 1/12 octave band centre frequency of maximum distance are also presented.

\begin{tabular}{|c|c|c|c|c|c|c|}
\hline \multirow{2}{*}{ Call data set } & \multirow{2}{*}{ Noise environment } & \multicolumn{3}{|c|}{ Max distance $(\mathrm{m})$} & \multicolumn{2}{|c|}{ Frequency of max distance $(\mathrm{Hz})$} \\
\hline & & Median & IQ range & $\%$ reduction & Median & IQ range \\
\hline \multirow[t]{2}{*}{ Adults/sub-adults, DTAGs SLE } & No boats & 6680 & $3370-20990$ & 57 & 4870 & $4340-6494$ \\
\hline & Boats & 2890 & $1220-8900$ & & 4870 & 4870-9173 \\
\hline \multirow[t]{2}{*}{ Adult female, aquarium } & No boats & 2330 & $1730-3780$ & 36 & 11548 & $10292-13725$ \\
\hline & Boats & 1490 & $860-2430$ & & 13725 & $11548-13725$ \\
\hline \multirow[t]{2}{*}{ Newborn, aquarium } & No boats & 360 & $140-1070$ & 53 & 3255 & $2738-4097$ \\
\hline & Boats & 170 & $60-390$ & & 3255 & $1223-36517$ \\
\hline
\end{tabular}

aquarium female's contact calls, which had a median of $2.3 \mathrm{~km}$ (IQ range $1.7-3.9 \mathrm{~km}$ ) in the absence of boats, with a potential $36 \%$ reduction in range in the presence of boat noise.

For comparison, the median distance at which all $1 / 12$ octave bands in the broadband calls emitted by wild belugas would be audible by a conspecific was much smaller (given the poor transmission of the very high-frequency components of these broadband calls). This was the case both in the absence of boats $(40 \mathrm{~m})$ and in their presence $(20 \mathrm{~m})$, still showing a $50 \%$ reduction. The range at which half of the $1 / 12$ th octave bands reached an SNR > OdB was reduced by $39 \%$ with boats present (410-250 m).

The $1 / 12$ th octave frequency bands that were audible for the longest distances for the SLE calls had a median of $4.9 \mathrm{kHz}$ both in quiet and noisy conditions. This is near the frequency range of the putative signature element of the SLE calls, which had a median peak frequency of $4.8 \mathrm{kHz}(n=53)$. To illustrate the reduction in range in a single call for each one of the 1/12 octave bands analysed (centre frequencies 487-97 $163 \mathrm{~Hz}$ ), we selected the contact call from our SLE DTAG data set that had an ASL equalling the median ASL of the set (150.28 $\mathrm{dB}$ re $1 \mu \mathrm{Pa}$ at $1 \mathrm{~m}$ ). In the absence of boat noise, most $1 / 12$ octave bands between 2 and $10 \mathrm{kHz}$ would be audible to a conspecific between 1 and $3 \mathrm{~km}$ away (Fig. 7). The centre frequency of the 1/12 octave band that extends the furthest is $4.8 \mathrm{kHz}$ (reaching 3.5 $\mathrm{km})$. In the presence of boat noise, none of the $1 / 12$ octave bands would be audible beyond $700 \mathrm{~m}$ for this particular call.

Newborn calls. The median communication range for newborn beluga calls was only $360 \mathrm{~m}$ in the absence of boat noise (IQ range 140-1070 m) and might be reduced by $53 \%$, to a median of $170 \mathrm{~m}$ (IQ range $60-390 \mathrm{~m}$ ) in the presence of boat noise. The 1/12 octave frequency bands that were audible at the furthest distances had a 
(a) No boats

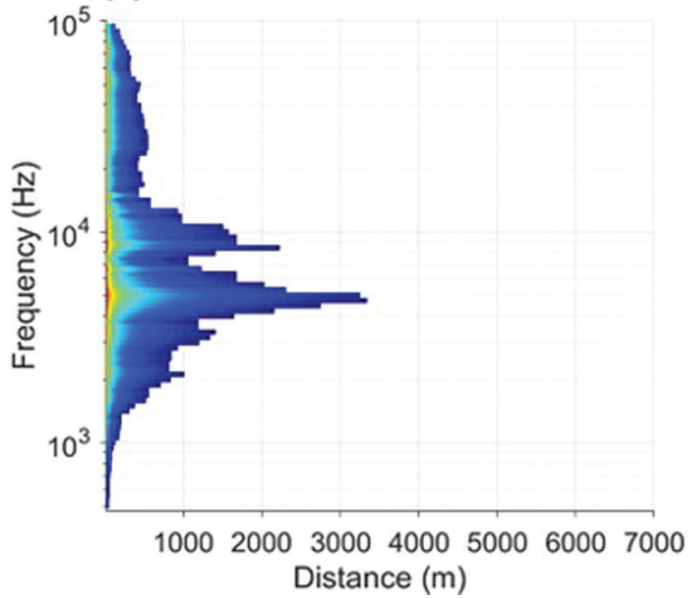

(b) Boats

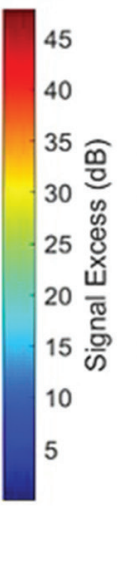

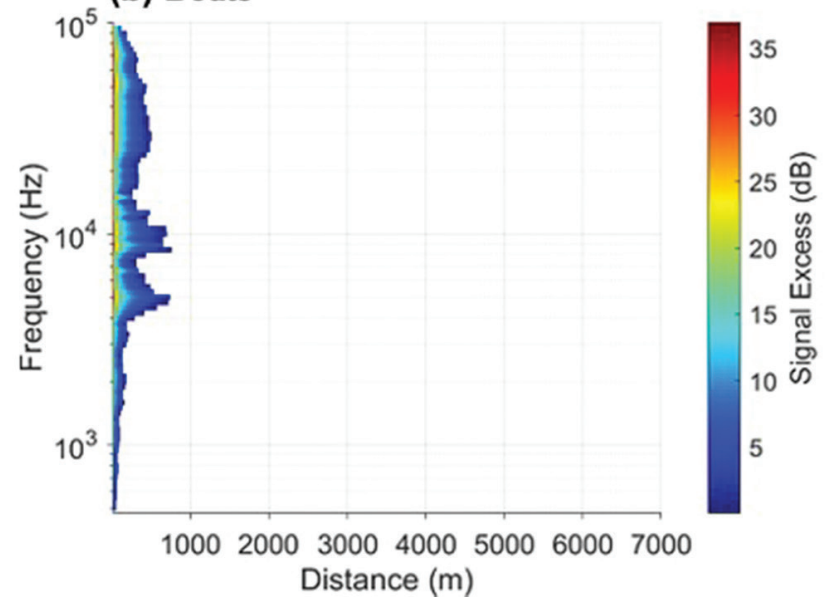

Fig. 7 Maximum communication range of each 1/12 octave band of a representative adult/sub-adult contact call in our data set (the call with the median source level) under 'no boats' (a) and boats (b) conditions. For each 1/12 octave band and at each distance, we subtracted the beluga hearing curve or the noise level, whichever was greater, from the received level. The 'signal excess' is the number of dB re $1 \mu \mathrm{Pa}$ that the beluga call is above the noise level or hearing curve.
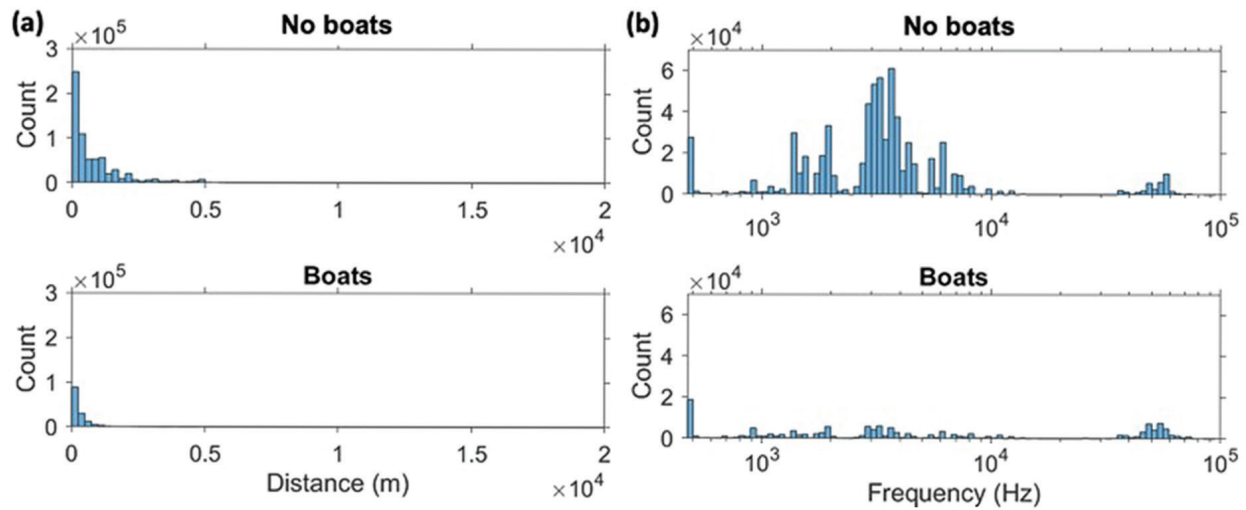

Fig. 8 Histograms showing distribution curves of modelled maximum communication ranges using calls recorded from a newborn beluga at Oceanogràfic (Valencia). (a) Maximum communication distances under (top) 'no boats' and (bottom) 'boats' scenarios. (b) 1/12 octave centre frequencies of maximum communication distances under (top) 'no boats' and (bottom) 'boats' scenarios. The count on the y axis is the number of model iterations for each combination of one call and one-minute noise file that falls in a specific distance or frequency bin.

median of $3.3 \mathrm{kHz}$ in the absence of boats, and $3.6 \mathrm{kHz}$ in boat noise (Fig. 8, Table 2).

Using the newborn call that had an SL equaling the median ASL of the set $(127 \mathrm{~dB}$ re $1 \mu \mathrm{Pa}$ at $1 \mathrm{~m}$, day 5 of life) to illustrate the potential reduction in range for each of the $1 / 12$ octave bands, the maximum audible distance in the absence of boats would be $300 \mathrm{~m}$, and less than 150 $\mathrm{m}$ in boat noise (Fig. 9).

\section{Discussion}

The mother-calf bond in belugas and other delphinids is maintained primarily through vision at close ranges
(Krasnova et al. 2009; Karenina et al. 2010; Hill et al. 2017) and acoustically when calves venture beyond a few metres, where visual contact becomes ineffective (e.g., Smolker et al. 1993). The present study provides the first data on ASLs and the communication range of contact calls in captive and wild belugas of different age classes. Previous studies had established that these calls are used between mothers and calves to regain or maintain contact with one another, and also by adults and juveniles for group cohesion (Vergara \& Barrett-Lennard 2008; Vergara et al. 2010), and the current study further confirms that these calls are used preferentially in herds with newborns. Despite the unavoidable shortcomings of all 
(a) No boats

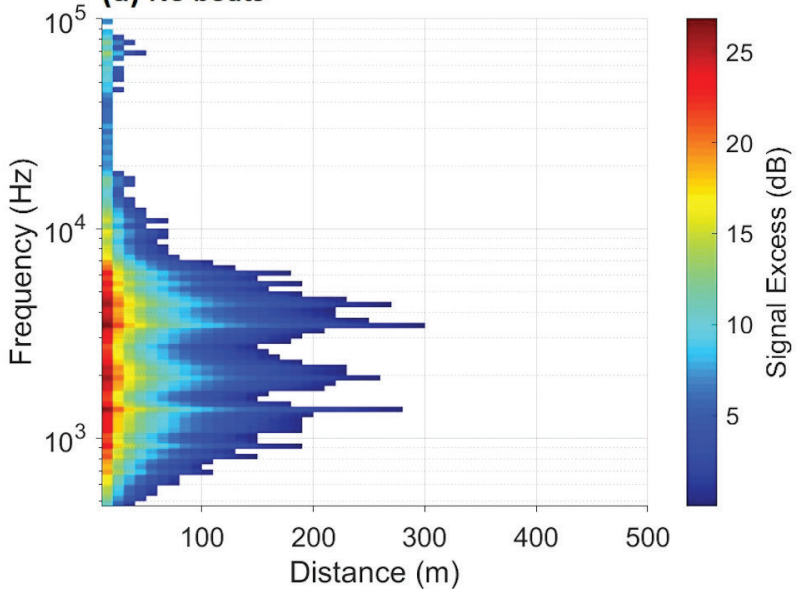

(b) Boats

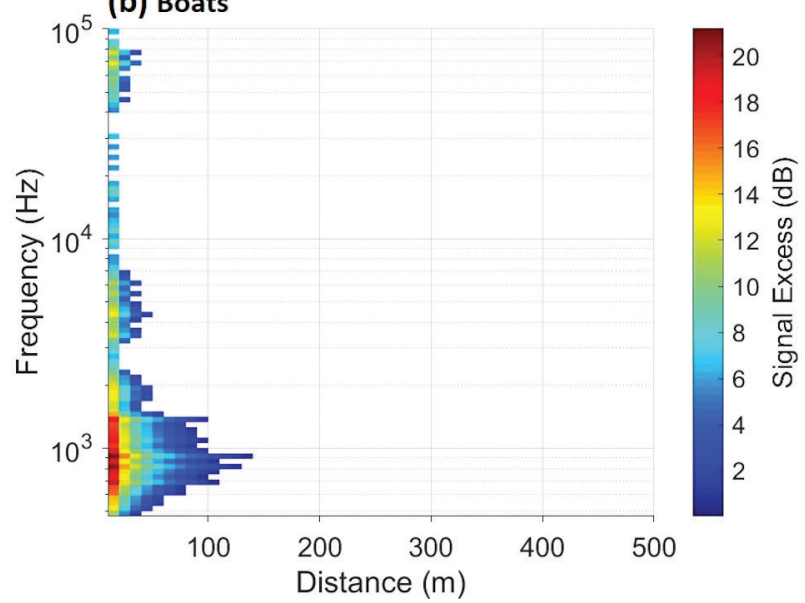

Fig. 9 Maximum communication range of each 1/12 octave band of a representative newborn beluga call in our data set (the call with the median source level, day 5 of life), under (a) 'no boats' and (b) 'boats' noise conditions. For each 1/12 octave band and at each distance, we subtracted the beluga hearing curve or the noise level, whichever was greater, from the received level. The 'signal excess' is the number of $d B$ re $1 \mu P a$ that the beluga call is above the noise level or hearing curve.

modelling in characterizing real world complexity (e.g., Tennessen \& Parks 2016), our study illustrates how changing levels of underwater noise affect the communication range of adult/sub-adult and infant belugas and demonstrates particularly strong masking effects for the underdeveloped calls of newborns.

SL measurements for aquatic species are difficult to obtain because the precise location of the vocalizing animals cannot always be determined accurately (Casey et al. 2016). The mean broadband ASLs of adult and subadult beluga contact calls reported here are within the range of $\mathrm{SL}_{\mathrm{rms}}$ of odontocete sounds reported in the literature, such as Indo-Pacific humpback dolphins (138.5 \pm 6.8 and $137.2 \pm 7.0 \mathrm{~dB}$ re $1 \mu \mathrm{Pa}$ depending on location [Wang et al. 2016]), killer whales (155.3 $\pm 6.5 \mathrm{~dB}$ re 1 $\mu \mathrm{Pa}$, Holt et al. 2011), Blainville's beaked whales (Mesoplodon densirostris; range $123-149 \mathrm{~dB}$ re $1 \mu \mathrm{Pa}$ [Aguilar de Soto et al. 2012]), bottlenose dolphins (158 \pm $0.6 \mathrm{~dB}$ re $1 \mu \mathrm{Pa}$ [Janik 2000]; $146.7 \pm 6.2 \mathrm{~dB}$ re $1 \mu \mathrm{Pa}$ [Jensen et al. 2012]; median $138 \mathrm{~dB}$ re $1 \mu \mathrm{Pa}$ [Frankel et al. 2014]), spotted dolphins (Stenella frontalis; median $138 \mathrm{~dB}$ re $1 \mu \mathrm{Pa}$ [Frankel et al. 2014]) and white-beaked dolphins (Lagenorhynchus albirostris; $148 \pm 12 \mathrm{~dB}$ re $1 \mu \mathrm{Pa}$ or $139 \pm 12 \mathrm{~dB}$ re $1 \mu \mathrm{Pa}$, depending on method [Rasmussen et al. 2006]). The only other study that documented SLs of beluga calls looked at narrow-band tonal signals rather than broadband pulsed calls and found a mean $\mathrm{SL}_{\mathrm{rms}}$ of $143.8 \pm 6.7 \mathrm{~dB}$ re $1 \mu \mathrm{Pa}$ at $1 \mathrm{~m}$, for a sample of 52 whistles with a dominant frequency between 1.5 and $5 \mathrm{kHz}$ (Le Bot et al. 2016).

Our modelled median communication ranges for adult and sub-adult beluga calls in the ambient noise levels of
Baie Sainte-Marguerite indicate a potential reduction to less than half the distance (57\% reduction) in the presence of boats. The only other published estimation of the communication range of a wild beluga call used a hypothetical narrowband beluga signal in natural ambient noise conditions and estimated a range of $4.5 \mathrm{~km}$ with a potential reduction in noise to $1.5 \mathrm{~km} 50 \%$ of the time and to $0.6 \mathrm{~km} 25 \%$ of the time in the high traffic area at the mouth of the Saguenay Fjord (Gervaise et al. 2012).

The detection range of individual vocalizations is greatly influenced by their SLs. We have shown here that newborn calves produce calls with ASLs that are on average 22 $\mathrm{dB}$ lower than adults or sub-adults, and that their calls are particularly weak during the first week of life. This corroborates previous studies that describe the initial pulse trains produced by a male beluga newborn calf at the Vancouver Aquarium as 'barely audible' low-energy calls (Vergara \& Barrett-Lennard 2008: 129), and those produced by two additional captive calves at the same aquarium as having low acoustic energy and slower pulse repetition rates relative to later calls (Vergara 2011). Our ASL estimates translate into a more restricted communication range (i.e., < $500 \mathrm{~m}$ ) for newborn beluga calls that can be nearly $5 \%$ that of adults and sub-adults. The modelled median communication range for the mother of this calf, which was about a third that of the SLE whales in quiet conditions (commensurate with the slightly lower ASLs of her calls), was still over six times the range of the soft calf calls.

Recent studies of calls produced by mother-calf pairs in mysticetes-humpback whales (Megaptera novaeangliae; Videsen et al. 2017), southern right whales (Eubalaena australis; Nielsen et al. 2019) and North Atlantic right 
whales (Eubalaena glacialis; Parks et al. 2019)-have also reported low output energy and small communication spaces, although this applied to both members of the pair, not only to the calves. In these studies, the importance of low-amplitude signals to maintain contact between mothers and calves is proposed as a cryptic strategy to reduce the risk of attracting aggressive male escorts among humpback whales or, for humpback, southern right and North Atlantic right whales, predators like killer whales and white sharks (Carcharodon carcharias). Belugas are also known to be preyed on by killer whales in various populations (Reeves \& Mitchell 1988; Frost et al. 1992; Shelden et al. 2003) and to use estuaries as a strategy to avoid such predation (Michaud 2005). Aggression by adult males towards newborn calves has been observed (Michaud, unpubl. data). In Russia's White Sea, beluga mothers tend to position themselves between their calves and approaching males, and beluga mother-calf pairs show evasive behaviour and leave the main group when males approach (Krasnova et al. 2006). In view of this, it is possible that the quiet calls of beluga newborn calves evolved as a cryptic strategy.

The small communication space of newborn beluga calls makes them particularly sensitive to increases in underwater noise, which can reduce a newborn call to a few tens of metres. The implications of these results for the ability of mothers and newborns to reunite when separated depend on the relative proximity maintained between mother and infant, a distance that changes as the calf acquires diving and social skills. Many cetacean calves remain in close proximity (within visual contact) to their mothers during the first few weeks of life, for example, bottlenose dolphins (Mann \& Smuts 1998, 1999), humpback whales (Szabo \& Duffus 2008) and southern right whales (Taber $\&$ Thomas 1982). Captive beluga calves initiate separations from their mothers almost immediately after birth, but these separations are limited to short distances of 1-5 m (Hill 2009). Wild beluga calves in the White Sea stay mostly in contact with their mother during the first days of life, and mothers impede all observed newborn attempts to swim farther than $2 \mathrm{~m}$ (Krasnova et al. 2009). Separations of only 2-3 $m$ begin on day 4 of life and can last over 10 seconds by day 10 (Krasnova et al. 2006). These swimming excursions away from the mother increase in frequency at 7-10 days of age, and, by two weeks of age, beluga calves can leave their mothers briefly and form transient associations with other calves and yearlings in the aggregation (Krasnova et al. 2006, 2009). How beluga mother-calf pairs use contact calls during separations and reunions, and which member of the pair might be responsible for initiating reunions is, however, unknown. In bottlenose dolphins, one study reported that infants produced the majority of the whistles during mother-calf separation contexts, but the study only analysed data for infants older than four months (Smolker et al. 1993). A follow-up study with a single mother-calf pair under human care showed that the maternal signature whistle is in fact important and is consistently used for mother-calf reunions; albeit data on neonates were not available in this study either (King et al. 2016).

Even if beluga newborns in their first few days of life do not separate from their mothers beyond distances that would compromise acoustic and visual contacts, unintentional separations to further distances may occur. These may be more likely during disturbance events. For example, mothers in pelagic dolphin species show flight behaviour during tuna purse-seine sets that may induce involuntary separations from their dependent calves that could increase the risk of mortality, especially for young animals under a year in age (Noren \& Edwards 2007). This is because calves following fleeing mothers simply fall too far behind due to the loss of the hydrodynamic connection with their mothers, or 'drafting' (Weihs 2004). Maternal flight responses that do not deviate from the fleeing behaviour of other adults, even at the expense of the calf, have also been documented in terrestrial herd mammals. Barren-ground caribou (Rangifer tarandus groenlandicus) mothers run with the herd during perceived or real threats, causing temporary or permanent separations from their young (Lent 1966). Beluga females with calves in the White Sea are the first to flee in response to danger (Krasnova et al. 2009). It is not implausible that in the SLE, involuntary separations may similarly occur in the face of some disturbances, and that noise may interfere with mother-calf reunions after such separations. A beluga newborn would conceivably hear the mother but may be too young to orient to her and find her, and the mother may simply not hear the calf, given the very short communication range of newborn calls in noise. The nature of the disturbances that could elicit flight reactions may depend on the level of habituation of belugas to such disturbances. In Baie SainteMarguerite, cargo ships may degrade the acoustic habitat but not cause a startle response, whereas recreational vessels approaching belugas at high speeds (against current regulations, but repeatedly observed by some of the authors) may elicit evasive behaviour.

The low ASLs of newborn calls also have important implications regarding a newborn's ability to compensate for noise. Marine mammals use a number of compensation strategies to improve signal detection in noisy environments, including longer calls, louder calls, increasing call rate, shifting the frequency of the signal outside the noise band, switching call types and waiting to call until noise decreases (see Tyack \& Janik 2013, for review). 
Evidence of these compensation strategies in odontocetes, including killer whales (Wieland et al. 2009; Holt et al. 2011 ), bottlenose dolphins (Au et al. 1982; Buckstaff 2004) and Indo-Pacific bottlenose dolphins (Morisaka, Shinohara, Nakahara et al. 2005), as well as belugas, is mounting. It is well known that belugas modify their vocal production in response to noise. For example, SLE belugas shift the mean frequencies of their calls upward (from $3.6 \mathrm{kHz}$ to $5.2-8.8$ $\mathrm{kHz}$ ) and increase the repetition rate of their whistles in the presence of small vessel and ferry noise (Lesage et al. 1999). They also increase the amplitude of their calls in response to noise, a mechanism known as the Lombard effect (Scheifele et al. 2005). Mackenzie River Estuary belugas may reduce their vocal production in response to vessel noise (Halliday et al. 2019). Belugas are also able to adapt their echolocation strategy in noisy environments by modifying the amplitude, spectral and temporal parameters of echolocation clicks (Au et al. 1985). However, beluga neonates may not be able to resort to these compensatory strategies. Pulse trains (rudimentary contact calls) are the only call type that they produce, expanding their repertoire as they age (Vergara $\&$ Barrett-Lennard 2008), and days-old calves may be physiologically unable to increase call amplitude or shift the peak energy of their pulse trains to higher frequencies (see Ames \& Vergara 2020). Ames \& Vergara (2020) showed that the peak frequencies of the calf's calls increased significantly over his first year of life and suggested that as belugas gain the ability to increase air pressure with age (which relates to an increase in SL [Cranford et al. 2000]), they may also gain the capacity to increase acoustic energy at higher frequencies (see Madsen et al. [2013] for correlation between SL and centre frequency).

The farthest range of adult and sub-adult calls coincided with the frequencies of the stereotyped putative signature elements of contact calls (Vergara \& Mikus 2019), which may have evolved for effective detection by conspecifics in the noisy and reverberant icy environment of the Arctic. The fact that beluga newborns only produce rudimentary, simple contact calls (Vergara \& Barrett-Lennard 2008; Ames \& Vergara 2020), which lack the overlapping tonal or pulsed tonal element of complex contact calls, may also explain their small communication ranges.

An important consideration is that we estimated communication range as the maximum distance at which the signal would still be audible by a conspecific in at least one of the $1 / 12$ octave bands analysed, not in all 1/12 bands. This is useful to understand how the various critical bands are affected differently by noise, and which frequency bands would remain audible at particular distances. However, it may be important for a conspecific to receive closer to the full signal to be able to decode it (see Brumm \& Slabbekoorn 2005). When we modelled the range within which half, and all, $1 / 12$ octave bands in the broadband calls would still be audible, the detection distances were, of course, considerably smaller, as these scenarios must take into account some or all of those very high-frequency bands that do not travel far in the first place, given the high absorption of high-frequency sounds. Therefore, the extent to which our communication range estimates reflect how far a calf would be able to recognize its mother acoustically by receiving and decoding her contact call is unknown. For a particular signal to confer an advantage to an individual (for example, to maintain contact with known individuals), detection alone may not be enough. A beluga would have to recognize and localize the call and then discriminate among signal types and possibly individual callers. Moving from detecting sounds in noise, to signal recognition and discrimination, to effective communication requires progressively higher SNRs (Erbe 2012; Reichmuth 2012). There is evidence from birds, for example, budgerigars (Melopsittacus undulatus) and zebra finches (Taeniopygia guttata; Lohr et al. 2003), that call discrimination is more difficult than call detection and has higher masked thresholds at a given level of noise (Lohr et al. 2003). In critical situations, masking-induced errors in the interpretation of signals by the receiver might incur biological costs. To date, there are no cetacean studies on the effect of acoustic masking on the recognition and discrimination of sounds. Future masking models would more closely approach real-world scenarios if they considered these biologically significant processes.

Our study, therefore, suffers from a number of evident shortcomings. The question of how many of the $1 / 12$ octave bands need to be audible for a call to not only just be detectable but also recognizable by conspecifics, remains. Our ASL estimations are, of course, not precise. Since the DTAGs are located on an off-axis position on the body of the whale, and behind the sound-generating structures (and thus not in the path of the acoustic beam of the whale), the ASLs estimated from the DTAGs AOLs are likely lower than true on-axis SLs (see Madsen et al. 2005; Johnson et al. 2006). Furthermore, our ASL estimates could not account for the directionality of contact calls, a factor known to affect SL among Hawaiian spinner dolphins (Stenella longirostris; Lammers et al. 2003) and bottlenose dolphins (Branstetter et al. 2012). Our communication range modelling did not include noise profile data obtained when belugas were present in the bay, so conspecific masking is not factored in our estimates. Considerations such as the temporal aspects of the vessel noise (frequency and duration of vessel transits through an area) and the effects of mitigation measures such as speed reduction were not examined in this paper. Finally, and perhaps of most relevance to the rationale 
behind this study, there is still some uncertainty about how often beluga calves separate from their mothers during the first month of life and to what distances and how long those separations last, especially in the SLE population. This information would be invaluable combined with data on the duration of loud masking events.

\section{Conclusion}

Although our estimates should be treated with caution, they are, to our knowledge, the only estimates of ASLs and communication range of beluga calls produced by different age classes and with a known critical function, that of establishing or maintaining contact between individuals, including mothers and calves. As such, they constitute an important step to understanding the potential effects of communication masking on mother-calf acoustic contact in this species. Given the magnitude of the difference in ASLs and communication ranges between adults and calves, we conclude that even if true SLs differ slightly from the ASLs we present here, they would be unlikely to affect main findings that vessel noise reduces communication range in belugas, and that these reductions may be particularly impactful for separated mother-calf pairs.

Given the sustained newborn mortality documented in recent years in SLE belugas (Mosnier et al. 2015; Gosselin et al. 2017), understanding all the factors that may contribute to this mortality and the long-standing lack of recovery of this population is important. Masking by anthropogenic noise is not an isolated disturbance but may act synergistically with other factors that can also affect survival and reproduction.

\section{Acknowledgements}

The authors thank Sépaq and Parks Canada for endorsing the temporary observation tower in Baie SainteMarguerite. The authors also thank Dr Kenneth Shorter (University of Michigan) for kindly providing expertise for DTAG calibration and settings, Michel Moisan and Timothée Perrero for their help with DTAG deployments and Jaclyn Aubin for assistance in the field. The authors are grateful to the anonymous reviewers whose constructive suggestions on earlier drafts of this manuscript contributed significantly to its quality. All research was conducted in accordance with the Canadian Council on Animal Care Guidelines for the Ethical Use and Care of Animals in Science and had approval from the Animal Care and Welfare Committee relating to the application for use of animals at Oceanogràfic (OCE-9-16,
OCE-14-18). The project also had permits for the use of DTAGS (IML-18-3), from Parks Canada (SAGMP-201621958 and SAGMP-2018-28758), from the Species at Risk Act (QUE-MM02-2016 and QUE-LEP-001-2018) and from Fisheries and Oceans Canada (IML-2018-024).

\section{Disclosure statement}

The authors report no conflict of interest.

\section{Funding}

This research has been supported by an AZA Conservation Grants Fund, Earth Rangers, Fondation de la Faune du Québec, Fisheries and Oceans Canada, and the Sea World $\&$ Busch Gardens Conservation Fund.

\section{References}

Aguilar de Soto N., Madsen P.T., Tyack P., Arranz P., Marrero J., Fais A., Revelli E. \& Johnson M. 2012. No shallow talk: cryptic strategy in the vocal communication of Blainville's beaked whales. Marine Mammal Science 28, E75-E92, doi: 10.1111/j.1748-7692.2011.00495.x.

Ames A.E. \& Vergara V. 2020. Trajectories of vocal repertoire development in beluga (Delphinapterus leucas) calves: insights from studies a decade apart. Aquatic Mammals 46, 344-366, doi: 10.1578/AM.46.4.2020.344.

Angiel N.M. 1997. The vocal repertoire of the beluga whale in Bristol Bay, Alaska. MSc thesis, University of Washington.

Au W.W.L. 1993. The sonar of dolphins. New York, NY: Springer.

Au W.W.L., Carder D.A., Penner R.H. \& Scronce B.L. 1985. Demonstration of adaptation in beluga whale echolocation signals. The Journal of the Acoustical Society of America 77, 726-730, doi: 10.1121/1.392341.

Au W.W.L., Ford J.K.B., Horne J.K. \& Allman K.A.N. 2004. Echolocation signals of free-ranging killer whales (Orcinus orca) and modeling of foraging for chinook salmon (Oncorhynchus tshawytscha). The Journal of the Acoustical Society of America 115, 901-909, doi: 10.1121/1.1642628.

Au W.W.L., Penner R.H. \& Kadane J. 1982. Acoustic behavior of echolocating Atlantic bottlenose dolphins. The Journal of the Acoustical Society of America 71, 1269-1275, doi: $10.1121 / 1.387733$.

Awbrey F.T., Thomas J.A. \& Kastelein R.A. 1988. Lowfrequency underwater hearing sensitivity in belugas, Delphinapterus leucas. The Journal of the Acoustical Society of America 84, 2273-2275, doi: 10.1121/1.397022.

Bain D.E. \& Dahlheim M.E. 1994. Effects of masking noise on detection thresholds of killer whales. In T.D. Loughlin (ed.): Marine mammals and the Exxon Valdez. Pp. 243-256. San Diego, CA: Academic Press.

Belikov R.A. \& Bel'kovich V.M. 2003. Underwater vocalization of the beluga whales (Delphinapterus leucas) in a reproductive gathering in various behavioral situations. Oceanology 43, 112-120. 
Belikov R.A. \& Bel'kovich V.M. 2006. High-pitched tonal signals of beluga whales (Delphinapterus leucas) in a summer assemblage off Solovetskii Island in the White Sea. Acoustical Physics 52, 125-131, doi: 10.1134/S1063771006020023.

Belikov R.A. \& Bel'kovich V.M. 2008. Communicative pulsed signals of beluga whales in the reproductive gathering off Solovetskii Island in the White Sea. Acoustical Physics 54, 115-123, doi: 10.1134/S1063771008010168.

Bojanowski E., Veit F. \& Todt D. 2000. The development of a bivocal signature whistle in a bottlenose dolphin calf. European Research on Cetaceans 14, 70-74.

Bowles A.E., Grebner D.M., Musser W.B., Nash J.S. \& Crance J.L. 2015. Disproportionate emission of bubble streams with killer whale biphonic calls: perspectives on production and function. The Journal of the Acoustical Society of America 137, EL165-EL170, doi: 10.1121/1.4905882.

Boyd I., Frisk G., Urban E., Tyack P., Ausubel J., Seeyave S., Cato D., Southall B., Weise M., Adrew R., Akamatsu T., Dekeling R., Erbe C., Farmer D., Gentry R., Gross T., Hawkins A., Li F., Metcalf K., Miller J.H., Moretti D., Rodrigo C. \& Shinke T. 2011. An international quiet ocean experiment. Oceanography 24, 174-181, doi: 10.5670/ oceanog.2011.37.

Branstetter B.K., Moore P.W., Finneran J.J., Tormey M.N. \& Aihara H. 2012. Directional properties of bottlenose dolphin (Tursiops truncatus) clicks, burst-pulse, and whistle sounds. The Journal of the Acoustical Society of America 131, 1613-1621, doi: 10.1121/1.3676694.

Brenowitz E. 1982. Long-range communication of species identity by song in the red-winged blackbird. Behavioral Ecology and Sociobiology 10, 29-38, doi: 10.1007/ BF00296393.

Brown Gladden J.G., Ferguson M.M., Friesen M.K. \& Clayton J.W. 1999. Population structure of North American beluga whales (Delphinapterus leucas) based on nuclear DNA microsatellite variation and contrasted with the population structure revealed by mitochondrial DNA variation. Molecular Ecology 8, 347-363, doi: 10.1046/j.1365-294X.1998.00559.x.

Brumm H. \& Slabbekoorn H. 2005. Acoustic communication in noise. Advances in the Study of Behavior 35, 151-209, doi: 10.1016/S0065-3454(05)35004-2.

Buckstaff K.C. 2004. Effects of watercraft noise on the acoustic behavior of bottlenose dolphins. Tursiops truncatus, in Sarasota Bay, Florida. Marine Mammal Science 20, 709-725, doi: 10.1111/j.1748-7692.2004.tb01189.x.

Caldwell M.C. \& Caldwell D.K. 1965. Individualized whistle contours in bottle-nosed dolphins (Tursiops truncatus). Nature 207, 434-435, doi: 10.1038/207434a0.

Casey C., Sills J. \& Reichmuth C. 2016. Source level measurements for harbor seals and implications for estimating communication space. Proceedings of Meetings on Acoustics 27, article no. 010034, doi: 10.1121/2.0000353.

Castellote M., Mooney T.A., Quakenbush L., Hobbs R., Goertz C. \& Gaglione E. 2014. Baseline hearing abilities and variability in wild beluga whales (Delphinapterus leucas). Journal of Experimental Biology 217, 1682-1691, doi:10.1242/jeb.093252
Clark C.W., Ellison W.T., Southall B.L., Hatch L., Van Parijs S.M., Frankel A. \& Ponirakis D. 2009. Acoustic masking in marine ecosystems: intuitions, analysis, and implication. Marine Ecology Progress Series 395, 201-222, doi: 10.3354/ meps08402.

Cranford T.W., Amundin M. \& Norris K. S. 1996. Functional morphology and homology in the odontocete nasal complex: implications for sound generation. Journal of Morphology 228, 223-285, doi: 10.1002/(sici) 10974687(199606)228:3<223::aid-jmor l>3.0.co;2-3.

Cranford T.W., Elsberry W.R., Blackwood D.J., Carr J.A., Kamolnick T., Todd M., Van Bonn W.G., Carder D.A., Ridgway S.H., Bozlinski D.M. \& Decker E.C. 2000. Two independent sonar signal generators in the bottlenose dolphin: physiologic evidence and implications. The Journal of the Acoustical Society of America 108, 2613-2614, doi: $10.1121 / 1.4743727$.

COSEWIC 2014. COSEWIC assessment and status report on the beluga whale, Delphinapterus leucas, St. Lawrence Estuary population, in Canada. Ottawa: Committee on the Status of Endangered Wildlife in Canada.

DFO 2014. Status of beluga (Delphinapterus leucas) in the St. Lawrence River Estuary. DFO Canadian Science Advisory Secretariat Science Advisory Report 2013/076. Ottawa: Fisheries and Oceans Canada.

DFO 2017. Review of the effectiveness of recovery measures for St. Lawrence Estuary beluga. Ottawa: Fisheries and Oceans Canada.

DFO 2018. Potential effects of the construction of marine terminals in the Saguenay Fjord on the St. Lawerence beluga whale and its habitat. DFO Canadian Science Advisory Secretariat Science Response 2018/025. Ottawa: Fisheries and Oceans Canada.

DFO 2020. Action plan to reduce the impact of noise on the beluga whale and other marine mammals at risk in the St. Lawrence Estuary. Ottawa: Fisheries and Oceans Canada.

Duarte de Figueiredo L. \& Simão S.M. 2009. Possible occurrence of signature whistles in a population of Sotalia guianensis (Cetacea, Delphinidae) living in Sepetiba Bay, Brazil. The Journal of the Acoustical Society of America 126, 1563-1569, doi: 10.1121/1.3158822.

Erbe C. 2000. Detection of whale call in noise: performance comparison between a beluga whale, human listeners, and a neural network. The Journal of the Acoustical Society of America 108, 297-303, doi: $10.1121 / 1.429465$.

Erbe C. 2012. Effects of underwater noise on marine mammals. In A.N. Popper \& A.D. Hawkins (eds.): Effects of noise on aquatic life. Pp. 17-22, New York: Springer.

Erbe C. \& Farmer D.M. 1998. Masked hearing thresholds of a beluga whale (Delphinapterus leucas) in icebreaker noise. Deep Sea Research Part II 45, 1373-1388, doi: 10.1016/ S0967-0645(98)00027-7.

Erbe C., Reichmuth C., Cunningham K., Lucke K. \& Dooling R. 2016. Communication masking in marine mammals: a review and research strategy. Marine Pollution Bulletin 103, 15-38, doi: 10.1016/j. marpolbul.2015.12.007. 
Faucher A. 1988. The vocal repertoire of the St. Lawrence Estuary population of beluga whale (Delphinapterus leucas) and its behavioural, social and environmental contexts. MSc thesis, Dalhousie University, Halifax.

Finneran J.J., Carder D.A., Dear R., Belting T., McBain J., Dalton L. \& Ridgway S.H. 2005. Pure tone audiograms and possible aminoglycoside-induced hearing loss in belugas (Delphinapterus leucas). The Journal of the Acoustical Society of America 117, 3936-3943, doi: 10.1121/1.1893354.

Finneran J.J., Schlundt C.E., Dear R., Carder D.A. \& Ridgway S.H. 2002. Temporary shift in masked hearing thresholds in odontocetes after exposure to single underwater impulses from a seismic watergun. The Journal of the Acoustical Society of America 111, 2929-2940, doi: 10.1121/1.1479150.

Fish M. \& Mowbray W. 1962. Production of underwater sounds by the white whale or beluga, Delphinapterus leucas. Journal of Marine Research 20, 149-162.

Frankel A.S., Zeddies D., Simard P. \& Mann D. 2014. Whistle source levels of free-ranging bottlenose dolphins and Atlantic spotted dolphins in the Gulf of Mexico. The Journal of the Acoustical Society of America 135, 1624-1631, doi: $10.1121 / 1.4863304$.

Fripp D. \& Tyack P. 2008. Postpartum whistle production in bottlenose dolphins. Marine Mammal Science 24, 479-502, doi: $10.1111 / \mathrm{j} .1748-7692.2008 .00195 . x$.

Frost K.J., Russel R.B. \& Lowry L.B. 1992. Killer whales, Orcinus orca, in the southeastern Bering Sea: recent sightings and predation on other marine mammals. Marine Mammal Science 8, 110-119, doi: 10.1111/j.17487692.1992.tb00370.x.

Gervaise C., Simard Y., Roy N., Kinda B. \& Ménard N. 2012. Shipping noise in whale habitat: characteristics, sources, budget, and impact on belugas in Saguenay-St Lawrence Marine Park hub. The Journal of the Acoustical Society of America 132, 76-89, doi:10.1121/1.4728190

Gosselin J.-F., Hammill M.O., Mosnier A. \& Lesage V. 2017. Abundance index of St. Lawrence Estuary beluga, Delphinapterus leucas, from aerial visual surveys flown in August 2014 and an update on reported deaths. DFO Canadian Science Advisory Secretariat Research Document 2017/019. Ottawa: Fisheries and Oceans Canada.

Halliday W.D., Scharffenberg K., MacPhee S., Hilliard R.C., Mouy X., Whalen D., Loseto L.I., \& Insley S.J. 2019. Beluga vocalizations decrease in response to vessel traffic in the Mackenzie River Estuary. Arctic 72, 337-346, doi: 10.14430/arctic69294.

Hill H.M. 2009. The behavioral development of two beluga calves during the first year of life. International Journal of Comparative Psychology 22, 234-253.

Hill H.M., Guarino S., Calvillo A., Gonzalez A., Zuniga K., Bellows C., Polasek L. \& Sims C. 2017. Lateralized swim positions are conserved across environments for beluga (Delphinapterus leucas) mother-calf pairs. Behavioural Processes 138, 22-28, doi: 10.1016/j.beproc.2017.01.018.

Holt M.M., Noren D.P. \& Emmons C.K. 2011. Effects of noise levels and call types on the source levels of killer whale calls. The Journal of the Acoustical Society of America 130, 3100-3106, doi: 10.1121/1.3641446.
Janik V.M. 2000. Source levels and the estimated active space of bottlenose dolphin (Tursiops truncatus) whistles in the Moray Firth, Scotland. Journal of Comparative Physiology A 186, 673-680, doi: 10.1007/s003590000120.

Janik V.M. \& Sayigh L.S. 2013. Communication in bottlenose dolphins: 50 years of signature whistle research. Journal of Comparative Physiology A 199, 479-489, doi:10.1007/ s00359-013-0817-7.

Jensen F.H., Beedholm K., Wahlberg M., Bejder L. \& Madsen P.T. 2012. Estimated communication range and energetic cost of bottlenose dolphin whistles in a tropical habitat. The Journal of the Acoustical Society of America 131, 582-592, doi: 10.1121/1.3662067.

Jensen F.H, Bejder L., Wahlberg M., Aguilar de Soto N., Johnson M. \& Madsen P. 2009. Vessel noise effects on delphinid communication. Marine Ecology Progress Series 395, 161-175, doi: 10.3354/meps08204.

Jensen F.H., Bejder L., Wahlberg M. \& Madsen P.T. 2009. Biosonar adjustments to target range of echolocating bottlenose dolphins (Tursiops sp) in the wild. Journal of Experimental Biology 212, 1078-1086, doi: 10.1242/ jeb.025619.

Jensen F.H., Keller O.A., Tyack P.L. \& Visser F. 2020. Dynamic biosonar adjustment strategies in deep-diving Risso's dolphins driven partly by prey evasion. Journal of Experimental Biology 223, jeb.216283, doi: 10.1242/jeb.216283.

Johnson C.S., McManus M.W. \& Skaar D. 1989. Masked tonal hearing thresholds in the beluga whale. The Journal of the Acoustical Society of America 85, 2651-2654, doi: $10.1121 / 1.397759$.

Johnson M., Madsen P.T., Zimmer W.M.X., Aguilar de Soto N. \& Tyack P.L. 2006. Foraging Blainville's beaked whales (Mesoplodon densirostris) produce distinct click types matched to different phases of echolocation. Journal of Experimental Biology 209, 5038-5050, doi: 10.1242/ jeb.02596.

Johnson M.P. \& Tyack P.L. 2003. A digital acoustic recording tag for measuring the response of wild marine mammals to sound. IEEE Journal of Oceanic Engineering 28, 3-12, doi: 10.1109/JOE.2002.808212.

Karenina K., Giljov A., Baranov V., Osipova L., Krasnova V. \& Malashichev Y. 2010. Visual laterality of calf-mother interactions in wild whales. PLoS One 5, 5-11, doi: 10.1371/ journal.pone.0013787.

Karlsen J.D., Bisther A., Lydersen C., Haug T. \& Kovacs K.M. 2002. Summer vocalisations of adult male white whales (Delphinapterus leucas) in Svalbard, Norway. Polar Biology 25, 808-817, doi: 10.1007/s00300-002-0415-6.

Kasuya T. 1995. Overview of cetacean life histories: an essay in their evolution. Developments in Marine Biology 4, 481497, doi: 10.1016/S0163-6995(06)80048-X.

Killebrew D.A., Mercado E. III, Herman L.H. \& Pack A.A. 2001. Sound production of a neonate bottlenose dolphin. Aquatic Mammals 27, 34-44.

King S.L., Guarino E., Keaton L., Erb L. \& Jaakkola K. 2016. Maternal signature whistle use aids mother-calf reunions in a bottlenose dolphin Tursiops truncatus. Behavioural Processes 126, 64-70, doi: 10.1016/j.beproc.2016.03.005. 
Klishin V.O., Popov V.V \& Supin A.Y. 2000. Hearing capabilities of a beluga whale, Delphinapterus leucas. Aquatic Mammals 26, 212-228.

Krasnova V.V., Bel'kovich V.M. \& Chernetsky [Chernetskii] A.D. 2006. Mother-infant spatial relations in wild beluga (Delphinapterus leucas) during postnatal development under natural conditions. Biology Bulletin 33, 53-58, doi: 10.1134/S1062359006010079.

Krasnova V.V., Bel'kovich V.M. \& Chernetskii [Chernetsky] A.D. 2009. Formation of behavior in the White Sea beluga calf, Delphinapterus leucas, during early postnatal ontogenesis. Russian Journal of Marine Biology 35, 53-59, doi: 10.1134/S1063074009010088.

Laerd Statistics 2016. Test of two proportions using SPSS statistics. Statistical tutorials and sofware guides. Accessed on the internet at https://statistics.laerd.com/ on 15 November 2020.

Lair S., Measures L.N. \& Martineau D. 2016. Pathologic findings and trends in mortality in the beluga (Delphinapterus leucas) population of the St Lawrence Estuary, Quebec, Canada, from 1983 to 2012. Veterinary Pathology 53, 22-36, doi: 10.1177/0300985815604726.

Lammers M.O., Au W.W.L. \& Herzing D.L. 2003. The broadband social acoustic signaling behavior of spinner and spotted dolphins. The Journal of the Acoustical Society of America 114, 1629-1639, doi: 10.1121/1.1596173.

Le Bot O., Simard Y., Roy N. \& Edric Gervaise C. 2016. Whistle source levels of free-ranging beluga whales in Saguenay-St. Lawrence marine park. The Journal of the Acoustical Society of America 140, EL89-EL93, doi: $10.1121 / 1.4955115$.

Lefebvre S.L., Michaud R., Lesage V. \& Berteaux D. 2012. Identifying high residency areas of the threatened St Lawrence beluga whale from fine-scale movements of individuals and coarse-scale movements of herds. Marine Ecology Progress Series 450, 243-257, doi: 10.3354/meps09570.

Lent P.C. 1966. Calving and related social behavior in the Barren-Ground Caribou. Zeitschrift fuer Tierpsychologie 23, 701-756, doi: 10.1111/j.1439-0310.1966.tb01707.x.

Lesage V., Barrette C., Kingsley M.C.S. \& Sjare B. 1999. The effects of vessel noise on the vocal behaviour of belugas in the St Lawrence Estuary, Canada. Marine Mammal Science 15, 65-84, doi: 10.1111/j.1748-7692.1999. tb00782.x.

Lesage V., McQuinn I.H., Carrier D., Gosselin J.F. \& Mosnier A. 2014. Exposure of the beluga (Delphinapterus leucas) to marine traffic under various scenarios of transit route diversion in the St. Lawrence Estuary. DFO Canadian Science Advisory Secretariat Research Document 2013/125. Ottawa: Fisheries and Oceans Canada.

Lesage V., Measures L., Mosnier A., Lair S., Michaud R. \& Béland P. 2014. Mortality patterns in St. Lawrence Estuary beluga (Delphinapterus leucas), inferred from the carcass recovery data, 1983-2012. DFO Canadian Science Advisory Secretariat Research Document 2013/118. Ottawa: Fisheries and Oceans Canada.

Lima A. \& Le Pendu Y. 2014. Evidence for signature whistles in Guiana dolphins (Sotalia guianensis) in Ilhéus, northeastern Brazil. The Journal of the Acoustical Society of America 136, 3178-3185, doi: 10.1121/1.4900829.

Lohr B., Wright T.F. \& Dooling R.J. 2003. Detection and discrimination of natural calls in masking noise by birds: estimating the active space of a signal. Animal Behaviour 65, 763-777, doi:10.1006/anbe.2003.2093

Madsen P.T., Lammers M., Wisniewska D. \& Beedholm K. 2013. Nasal sound production in echolocating delphinids (Tursiops truncatus and Pseudorca crassidens) is dynamic, but unilateral: clicking on the right side and whistling on the left side. Journal of Experimental Biology 216, 4091-4102, doi: 10.1242/jeb.091306.

Madsen P.T., Johnson M., Aguilar de Soto N., Zimmer W.M.X. \& Tyack P. 2005. Biosonar performance of foraging beaked whales (Mesoplodon densirostris). Journal of Experimental Biology 208, 181-194, doi: 10.1242/jeb.01327.

Mann J. \& Smuts B.B. 1998. Natal attraction: allomaternal care and mother-infant separations in wild bottlenose dolphins. Animal Behaviour 55, 1097-1113, doi: 10.1006/ anbe.1997.0637.

Mann J. \& Smuts B.B. 1999. Behavioral development of wild bottlenose dolphin newborns (Tursiops sp). Behavioral Ecology and Sociobiology 136, 529-566, doi: 10.1163/156853999501469.

Marten K. \& Marler P. 1977. Sound transmission and its significance for animal vocalization. Behavioral Ecology and Sociobiology 2, 271-290, doi: 10.1007/BF00299740.

Martin P. \& Bateson P. 2007. Measuring behaviour. Cambridge: Cambridge University Press.

McCowann B. \& Reiss D. 1995. Whistle contour development in captive-born infant bottle-nosed dolphins (Tursiopstruncatus) - role of learning. Journal of Comparative Psychology 109, 242-260, doi: 10.1037/0735-7036.109.3.242.

McQuinn I.H., Lesage V., Carrier D., Larrivée G., Samson Y., Chartrand S., Michaud R. \& Theriault J. 2011 . A threatened beluga (Delphinapterus leucas) population in the traffic lane: vessel-generated noise characteristics of the Saguenay-St. Lawrence Marine Park, Canada. The Journal of the Acoustical Society of America 130, 3661-3673, doi: 10.1121/1.3658449.

Mello I. \& Amundin M. 2005. Whistle production pre- and post-partum in bottlenose dolphins (Tursiops truncatus) in human care. Aquatic Mammals 31, 169-175, doi: 10.1578/ AM.31.2.2005.169.

Ménard N., Michaud R., Chion C. \& Turgeon S. 2014. Documentation of maritime traffic and navigational interactions with St Lawrence Estuary beluga (Delphinaterus leucas) in calving areas between 2003 and 2012. DFO Canadian Science Advisory Secretariat Research Document 2014/003. Ottawa: Fisheries and Oceans Canada.

Merchant N.D., Fristrup K.M., Johnson M.P., Tyack P.L., Witt M.J., Blondel P. \& Parks S.E. 2015. Measuring acoustic habitats. Methods in Ecology and Evolution 6, 257-265, doi: 10.1111/2041-210X.12330.

Michaud R. 2005. Sociality and ecology in odontocetes. In K.E. Ruckstuhi \& P. Neuhaus (eds.): Sexual segregation in vertebrates: ecology of the two sexes. Pp. 303-326. Cambridge: Cambridge University Press.

Miller P.J.O. 2006. Diversity in sound pressure levels and estimated active space of resident killer whale vocalizations. 
Journal of Comparative Physiology A 192, 449-459, doi: 10.1007/s00359-005-0085-2.

Mishima Y., Morisaka T., Itoh M., Matsuo I., Sakaguchi A. \& Miyamoto Y. 2015. Individuality embedded in the isolation calls of captive beluga whales (Delphinapterus leucas). Zoological Letters 1, article no. 27, doi: 10.1186/s40851-015-0028-x.

Mohl B., Wahlberg M., Madsen P.T., Miller L.A. \& Surlykke A. 2000. Sperm whale clicks: directionality and source level revisited. The Journal of the Acoustical Society of America 107, 638-648, doi: 10.1121/1.428329.

Mooney T.A., Nachtigall P.E., Castellote M., Taylor K.A., Pacini A.F. \& Esteban J.A. 2008. Hearing pathways and directional sensitivity of the beluga whale, Delphinapterus leucas. Journal of Experimental Marine Biology and Ecology 362, 108-116, doi: 10.1016/j.jembe.2008.06.004.

Morisaka T., Shinohara M., Nakahara F. \& Akamatsu T. 2005. Effects of ambient noise on the whistles of Indo-Pacific bottlenose dolphin populations. Journal of Mammalogy 86, 541-546, doi: 10.1644/1545-1542(2005)86[541:EOANOT ]2.0.CO;2.

Morisaka T., Shinohara M. \& Taki M. 2005. Underwater sounds produced by neonatal bottlenose dolphins (Tursiops truncatus): I. Acoustic characteristics. Aquatic Mammals 31, 248-257, doi: 10.1578/AM.31.2.2005.248.

Morisaka T., Yoshida Y., Akune Y., Mishima H. \& Nishimoto S. 2013. Exchange of "signature" calls in captive belugas (Delphinapterus leucas). Journal of Ethology 31, 141-149, doi: 10.1007/s10164-013-0358-0.

Mosnier A., Doniol-Valcroze T., Gosselin J.F., Measures L.N. \& Hammill M.O. 2015. Insights into processes of population decline using an integrated population model: the case of the St Lawrence Estuary beluga (Delphinapterus leucas). Ecological Modelling 314, 15-31, doi: 10.1016/j. ecolmodel.2015.07.006.

Nedelec S.L., Radford A.N., Simpson S.D., Nedelec B., Lecchini D. \& Mills S.C. 2014. Anthropogenic noise playback impairs embryonic development and increases mortality in a marine invertebrate. Scientific Reports 4, article no. 5891, doi: 10.1038/srep05891.

Nielsen M.L.K., Bejder L., Videsen S.K.A., Christiansen F. \& Madsen P.T. 2019. Acoustic crypsis in southern right whale mother-calf pairs: infrequent, low-output calls to avoid predation? Journal of Experimental Biology 222, jeb190728, doi: 10.1242/jeb.190728.

Noren S.R. \& Edwards E.F. 2007. Physiological and behavioral development in delphinid calves: implications for calf separation and mortality due to tuna purse-seine sets. Marine Mammal Science 23, 15-29, doi: 10.1111/j.1748-7692.2006.00083.x.

Panova E., Agafonov A., Belikov R. \& Melnikova F. 2017. Vocalizations of captive beluga whales, Delphinapterus leucas: additional evidence for contact signature "mixed" calls in belugas. Marine Mammal Science 33, 889-903, doi: $10.1111 / \mathrm{mms} .12393$.

Panova E.M., Belikov R.A., Agafonov A.V. \& Bel'kovich V.M. 2012. The relationship between the behavioral activity and the underwater vocalization of the beluga whale (Delphinapterus leucas). Oceanology 52, 79-87, doi: 10.1134/ S000143701201016X.
Parks S.E., Cusano D.A., Van Parijs S.M. \& Nowacek D.P. 2019. Acoustic crypsis in communication by North Atantic right whale mother-calf pairs on the calving grounds. Biology Letters 15, article no. 20190485, doi: 10.1098/ rsbl.2019.0485.

Perez J.M., Jensen F.H., Rojano-Doñate L. \& Aguilar de Soto N. 2017. Different modes of acoustic communication in deep-diving short-finned pilot whales (Globicephala macrorhynchus). Marine Mammal Science 33, 59-79, doi: 10.1111/ mms.12344.

Popov V. \& Supin A. 1990. Electrophysiological studies of hearing in some cetaceans and a manatee. In J.A. Thomas \& R.A. Kastelein (eds.): Sensory abilities of cetaceans: laboratory and field evidence. Pp. 405-415. New York: Plenum Press.

Popper A.N. \& Hastings M.C. 2009. The effects of human-generated sound on fish. Integrative Zoology 4, 43-52, doi: 10.1111/j.1749-4877.2008.00134.x.

Postma L.D. 2017. Genetic diversity, population structure and phylogeography among belugas (Delphinapterus leucas) in Canadian waters: broad to fine-scale approaches to inform conservation and management strategies. PhD thesis, University of Manitoba, Winnipeg.

Rasmussen M.H., Lammers M., Beedholm K. \& Miller L.A. 2006. Source levels and harmonic content of whistles in white-beaked dolphins (Lagenorhynchus albirostris). The Journal of the Acoustical Society of America 120, 510-517, doi: $10.1121 / 1.2202865$.

Reeves R.R. \& Mitchell E. 1988. Distribution and seasonality of killer whales in the eastern Canadian Arctic. Rit Fiskideildar 11, 136-160.

Reichmuth C. 2012. Psychophysical studies of auditory masking in marine mammals: key concepts and new directions. Advances in Experimental Medicine and Biology 730, 23-27, doi: 10.1007/978-1-4419-7311-5_4.

Richardson W.J., Greene C.R., Malme C.I. \& Thomson D.H. 1995. Marine mammals and noise. London: Academic Press.

Ridgway S.H., Carder D.A., Kamolnick T., Smith R.R., Schlundt C.E. \& Elsberry W.R. 2001. Hearing and whistling in the deep sea: depth influences whistle spectra but does not attenuate hearing by white whales (Delphinapterus leucas) (Odontoceti, Cetacea). Journal of Experimental Biology 204, 3829-3841, doi: 10.1242/ jeb.204.22.3829.

Saddler M.R., Bocconcelli A., Hickmott L.S., Chiang G., Landea-Briones R., Bahamonde P.A., Howes G., Segre P.S. \& Sayigh L.S. 2017. Characterizing Chilean blue whale vocalizations with DTAGs: a test of using tag accelerometers for caller identification. Journal of Experimental Biology 220, 4119-4129, doi: 10.1242/jeb.151498.

Scheifele P.M., Andrew S., Cooper R.A., Darre M., Musiek F.E. \& Max L. 2005. Indication of a lombard vocal response in the St Lawrence River beluga. The Journal of the Acoustical Society of America 117, 1486-1492, doi: 10.1121/1.1835508.

Shapiro A.D. 2006. Preliminary evidence for signature vocalizations among free-ranging narwhals (Monodon monoceros). The Journal of the Acoustical Society of America 120, 1695-1705, doi:10.1121/1.2226586

Shelden K., Rugh D., Mahoney B. \& Dahlheim M. 2003. Killer whale predation on belugas in Cook Inlet, Alaska: 
implications for a depleted population. Marine Mammal Science 19, 529-544, doi: 10.1111/j.1748-7692.2003. tb01319.x.

Simard Y., Lepage R. \& Gervaise C. 2010. Anthropogenic sound exposure of marine mammals from seaways: estimates for lower St Lawrence Seaway, eastern Canada. Applied Acoustics 71, 1093-1098, doi: 10.1016/J.APACOUST.2010.05.012.

Sjare B.L. \& Smith T.G. 1986a. The vocal repertoire of white whales, Delphinapterus leucas, summering in Cunningham Inlet, Northwest Territories. Canadian Journal of Zoology 64, 407-415, doi: 10.1139/z86-063.

Sjare B.L. \& Smith T.G. 1986b. The relationship between behavioral activity and underwater vocalizations of the white whale, Delphinapterus leucas. Canadian Journal of Zoology 64, 2824-2831, doi: 10.1139/z86-406.

Smolker R.A., Mann J. \& Smuts B.B. 1993. Use of signature whistles during separations and reunions by wild bottlenose dolphin mothers and infants. Behavioral Ecology and Sociobiology 33, 393-402, doi: 10.2307/4600898.

Southall B.L., Bowles A.E., Ellison W.T., Finneran J.J., Gentry R.L., Greene C.R. Jr., Kastak D., Ketten D.R., Miller J.H., Nachtigall P.E., Richardson J.W., Thomas J.A. \& Tyack P.L. 2007. Marine mammal noise exposure criteria: initial scientific recommendations. Aquatic Mammals 33, 273-275, doi: 10.1578/AM.33.4.2007.411.

Southall B.L., Finneran J.J., Reichmuth C., Nachtigall P.E., Ketten D.R., Bowles A.E., Ellison W.T., Nowacek D.P. \& Tyack P.L. 2019. Marine mammal noise exposure criteria: updated scientific recommendations for residual hearing effects. Aquatic Mammals 45, 125-232, doi: 10.1578/ AM.45.2.2019.125.

Szabo A. \& Duffus D. 2008. Mother-offspring association in the humpback whale, Megaptera novaeangliae: following behaviour in an aquatic mammal. Animal Behaviour 75, 1085-1092, doi: 10.1016/j.anbehav.2007.08.019.

Taber S. \& Thomas P. 1982. Calf development and mother-calf spatial relationships in southern right whales. Animal Behaviour 30, 1072-1083, doi: 10.1016/S0003-3472(82)80197.

Tennessen J.B. \& Parks S.E. 2016. Acoustic propagation modeling indicates vocal compensation in noise improves communication range for North Atlantic right whales. Endangered Species Research 30, 225-237, doi: 10.3354/esr00738.

Tervo O.M., Christoffersen M.F., Simon M., Miller L.A., Jensen F.H., Parks S.E. \& Madsen P.T. 2012. High source levels and small active space of high-pitched song in bowhead whales (Balaena mysticetus). PLoS One 7, e52072, doi: 10.1371/journal.pone.0052072.

Tyack P.L. \& Janik V.M. 2013. Effects of noise on acoustic signal production in marine mammals. In H. Brumm (ed.): Animal communication and noise. Vol. 2. Pp. 251-271. Berlin: Springer.
Van Parijs S.M. \& Corkeron P.J. 2001. Vocalizations and behaviour of Pacific humpback dolphins Sousa chinensis. Ethology 107, 701-716, doi: 10.1046/j.1439-0310. 2001.00714.x.

Vergara V. 2011. Acoustic communication and vocal learning in belugas (Delphinapterus leucas). PhD thesis, University of British Columbia.

Vergara V. \& Barrett-Lennard L.G. 2008. Vocal development in a beluga calf (Delphinapterus leucas). Aquatic Mammals 34, 123-143, doi: 10.1578/AM.34.1.2008.123.

Vergara V., Michaud R. \& Barrett-Lennard L.G. 2010. What can captive whales tell us about their wild counterparts? Identification, usage, and ontogeny of contact calls in belugas (Delphinapterus leucas). International Journal of Comparative Psychology 23, 278-309.

Vergara V. \& Mikus M.-A. 2019. Contact call diversity in natural beluga entrapments in an Arctic estuary: preliminary evidence of vocal signatures in wild belugas. Marine Mammal Science 35, 434-465, doi: 10.1111/mms.12538.

Videsen S.K.A., Bejder L., Johnson M. \& Madsen P.T. 2017. High suckling rates and acoustic crypsis of humpback whale neonates maximise potential for mother-calf energy transfer. Functional Ecology 31, 1561-1573, doi: $10.1111 / 1365-2435.12871$.

Wang Z.-T., Au W.L., Rendell L., Wang K., Wu H.-P., Wu Y., Liu J., Duan G. -Q., Cao H.-J., Wang D. 2016. Apparent source levels and active communication space of whistles of free-ranging Indo-Pacific humpback dolphins (Sousa chinensis) in the Pearl River Estuary and Beibu Gulf, China, PeerJ 4, el695, doi: 10.7717/peerj.1695.

Weihs D. 2004. The hydrodynamics of dolphin drafting. Journal of Biology 3, article no. 8.

Wenz G.M. 1962. Acoustic ambient noise in the ocean: spectra and sources. The Journal of the Acoustical Society of America 34, 1936-1956, doi: 10.1121/1.1909155.

White M.J. Jr., Norris J., Ljungblad D., Baron K. \& di Sciara G. 1978. Auditory thresholds of two beluga whales (Delphinapterus leucas). Technical Report 78-109. San Diego, CA: Hubbs Marine Research Institute.

Wieland M., Jones A. \& Renn S.C.P. 2009. Changing durations of southern resident killer whale (Orcinus orca) discrete calls between two periods spanning 28 years. Marine Mammal Science 26, 195-201, doi: 10.1111/j.1748-7692.2009.00351.x.

Williams R., Lacy R.C., Ashe E.E., Hall A., Lehoux C., Lesage V., Mcquinn I. \& Pourde S. 2017. Predicting responses of St. Lawrence beluga to environmental change and anthropogenic threats to orient effective management actions. DFO Canadian Science Advisory Secretariat Research Document 2017/027. Ottawa: Fisheries and Oceans Canada. 